NBER WORKING PAPER SERIES

\title{
THE IMPACT OF BANK CREDIT ON LABOR REALLOCATION AND AGGREGATE INDUSTRY PRODUCTIVITY
}

\author{
John (Jianqiu) Bai \\ Daniel Carvalho \\ Gordon M. Phillips \\ Working Paper 24081 \\ http://www.nber.org/papers/w24081 \\ NATIONAL BUREAU OF ECONOMIC RESEARCH \\ 1050 Massachusetts Avenue \\ Cambridge, MA 02138 \\ November 2017, Revised December 2017
}

We thank Manuel Adelino, Andrew Ellul, Mark Garmaise, John Haltiwanger, Javier Miranda, Marco Navone, Vincenzo Quadrini, Geoffrey Tate, Michael Roberts (The Editor), Jeremy Stein, Rene Stulz, Greg Udell, two anonymous referees, and seminar participants at the AFA meetings 2016, CSEF-EIEF-SITE Conference on Finance and Labor, FIRS conference, FMA meetings, Indiana University (Kelley), NBER Corporate Finance SI 2015, NBER CRIW SI 2015, Northeastern University, Ohio State (Fisher), UCLA, University of Florida, University of Maryland (Smith), USC Marshall, University of Toronto, University of Wisconsin-Madison, and Washington University at St. Louis (Olin) for helpful comments. John (Jianqiu) Bai is from Northeastern University, Carvalho is from Indiana University, and Phillips is from Tuck School of Business at Dartmouth College. All of the authors have read the Journal of Finance's disclosure policy and have no conflicts of interest to disclose. Any opinions and conclusions expressed herein are those of the author(s) and do not necessarily represent the views of the U.S. Census Bureau or the National Bureau of Economic Research. All results have been reviewed to ensure that no confidential information is disclosed.

NBER working papers are circulated for discussion and comment purposes. They have not been peer-reviewed or been subject to the review by the NBER Board of Directors that accompanies official NBER publications.

(C) 2017 by John (Jianqiu) Bai, Daniel Carvalho, and Gordon M. Phillips. All rights reserved. Short sections of text, not to exceed two paragraphs, may be quoted without explicit permission provided that full credit, including $\odot$ notice, is given to the source. 
The Impact of Bank Credit on Labor Reallocation and Aggregate Industry Productivity John (Jianqiu) Bai, Daniel Carvalho, and Gordon M. Phillips

NBER Working Paper No. 24081

November 2017, Revised December 2017

JEL No. G2,G21,G3,G31,G32,J01,J21,J24,L22,L23,L25,O11,O12

\begin{abstract}
We provide evidence that the deregulation of U.S. state banking markets leads to a significant increase in the relative employment and capital growth of local firms with higher productivity and that this effect is concentrated among young firms. Using financial data for a broad range of firms, our analysis suggests that this effect is driven by a shift in the composition of local bank credit supply towards more productive firms. We estimate that this effect translates into economically important gains in aggregate industry productivity and that changes in the allocation of labor play a central role in driving these gains.
\end{abstract}

John (Jianqiu) Bai

D'Amore-McKim School of Business

Northeastern University

j.bai@northeastern.edu

Daniel Carvalho

Kelly School of Business

Indiana University

Bloomington, IN 47405

daniel.rscarvalho@gmail.com
Gordon M. Phillips

Tuck School of Business

Dartmouth College

100 Tuck Hall

Hanover, NH 03755

and NBER

gordon.m.phillips@gmail.com

An online appendix is available at http://www.nber.org/data-appendix/w24081 
A growing body of evidence suggests that improvements in financial markets can significantly contribute to economic growth and argues that increases in aggregate productivity plays a central role in this process. ${ }^{1}$ Despite the importance of this idea, we still have limited direct evidence on the specific economic mechanisms through which finance affects growth and productivity. In this paper, we study the role of local U.S. banking markets in shifting the allocation of labor and capital within local industries towards firms with higher productivity. Intuitively, this reallocation effect changes the composition of the industry and plays an important role in increasing the industry's aggregate productivity as it allows the same aggregate resources to generate more output. ${ }^{2}$ Banks can potentially be important in shaping this composition effect because of their role in determining which firms are financed. Therefore, improvements in banking markets can lead to a more positive link between firm productivity and bank credit. We examine this idea and the importance of labor in this process. While labor is a central factor used in production, limited attention has been paid to the role of labor reallocation in explaining the effects of finance on aggregate productivity.

We study the importance of bank lending to both labor and capital reallocation in the context of major U.S. state banking deregulations, which reduced constraints on banks’ ability to expand across geographic markets and represent historically important changes in U.S. banking markets. An advantage of analyzing these reforms is that they capture focused changes in the degree of bank

\footnotetext{
${ }^{1}$ See Jayaratne and Strahan (1996), Beck, Levine, and Loayza (2000), Guiso, Sapienza, and Zingales (2004).

${ }^{2}$ Previous research has emphasized the role of this within-industry composition effect as a fundamental determinant of aggregate productivity (e.g., Olley and Pakes (1996), and Hsieh and Klenow (2009)). Differences in firm productivity are typically the fundamental source of firm heterogeneity emphasized in empirical studies and models of such composition effects (Bartelsman, Haltiwanger, and Scarpeta (2013)).
} 
competition in a local market. Broad patterns around these reforms have indicated that the previous reallocation effects appear to be important in driving higher economic growth during these episodes (Jayaratne and Strahan $(1996,1998))$. As banking markets become more competitive, banks - either new or existing banks facing competition - might improve the monitoring and screening of borrowers. For example, this can happen because of an improved selection mechanism for surviving banks or because of stronger incentives for performance faced by a given bank. As banks improve their screening of borrowers, they may be able to better detect higher productivity firms. Improvements in the monitoring of firms should make it easier for borrowers to pledge their future income. Firms with higher productivity can arguably benefit more from these improvements because they have more income to pledge.

However, in theory, the sign and magnitude of this effect are unclear. Increased bank entry might simply lead to reduction in market power and interest rates, increasing the availability of credit for all firms. Reductions in bank market power can also harm relationship formation (Petersen and Rajan (1995)) and simply lead banks to lend less to all small business. In addition, new (larger) banks entering a market might not have comparative advantage in small-business lending and might be worse in monitoring and screening these firms.

Empirically analyzing the importance of the previous reallocation effects has been difficult because of both data and identification challenges. This analysis requires micro-level data on small firms connecting both their real decisions and sources of external finance to their productivity and age. We analyze small firms by using firm- and plant-level data from the U.S. Census Bureau. Two recent studies by Kerr and Nanda (2009) and Krishnan, Nandy, and Puri (2014) also have used this data to analyze the effects of deregulation. However, these studies do not examine the reallocation of production from less productive to more productive firms, nor the impact on labor 
versus capital and lastly, do not study the bank financing patterns of these small firms. ${ }^{3}$ We also quantify the magnitudes of the industry productivity gains implied by our results. ${ }^{4}$

Our analysis is implemented with micro-level data from the U.S. Census Bureau on a broad sample of small U.S. manufacturing firms. This data allows us to relate both firms' real decisions and financial policies to measures of their multi-factor productivity estimated using plant-level data. We note that the previous reallocation effects should be mostly important for the youngest firms. Because of the past lending relationships of older firms, new firms should be more likely to borrow from new banks entering a market. If new banks change the composition of local credit supply, this effect should then mostly affect the youngest firms. Differences in the screening and monitoring of banks should also arguably matter more for young firms which have a limited track record. ${ }^{5}$ Additionally, these firms should depend more on external funds to finance their higher growth.

We start by analyzing how the relative growth of higher-productivity firms within a local industry changes after deregulation in their state. We separately estimate this effect across firm age groups and examine its differential importance for young existing firms. Our main results

\footnotetext{
${ }^{3}$ In their discussion of the mechanism through which deregulation matters, Jayaratne and Strahan (1996) explain that "To answer this question satisfactorily, we would like data on bank borrowers such as the productivity and longevity... especially among bank-dependent firms such as small business”.

${ }^{4}$ When examining implications for industry productivity, an important consideration is that firms affected by deregulation might represent a small portion of aggregate industry output. We explicitly incorporate this issue when quantifying the magnitudes of our results.

${ }^{5}$ As discussed in Section 1.2, previous evidence based on aggregate data from banks' balance sheets shows that these reforms were associated with a significant increase in the market share of better performing banks in deregulated states.
} 
employ a triple-difference framework, where we compare changes in the previous relative growth across states experiencing deregulation at different periods of time, and then contrast this effect for different age groups. We find that the deregulation is associated with an economically large increase in the relative growth of more productive, young firms. We find that this relative growth increase is important for both labor and capital, and that is not present for older firms. This increase in growth takes place right after deregulation and is not matched with pre-existing growth trends.

We then investigate the role of changes in the composition of credit supply in driving the previous growth effect. We first directly examine the importance of such changes in the composition of credit supply. As before, we separately examine different age groups and focus on differential patterns for young firms. In order to analyze the role of bank credit supply, as opposed to credit demand, we analyze how firms borrow across different sources of debt financing. Our data allows us to distinguish between debt from commercial banks (bank debt) and debt from other sources (non-bank debt), and deregulation only covered commercial banks. Consistent with previous research (Petersen and Rajan (1994)), we find that young and old small firms significantly rely on both bank and non-bank debt. We argue that changes in credit demand should affect firms' demand for both sources of debt financing. In contrast, increases in bank credit supply should lead to an increase in the share of total debt coming from banks for a given firm-year. We therefore estimate our results using this share of bank debt as an outcome. ${ }^{6}$ We find that deregulation is associated with a significant increase in the relative bank debt share of high-productivity firms. This effect is economically large for the young firms driving the previous growth results and is

\footnotetext{
${ }^{6}$ The basic idea of relying on the share of bank debt to isolate changes in bank credit supply is also used in Kashyap, Stein, and Wilcox (1993), and Becker and Ivashina (2014).
} 
limited for old firms where the growth effects are not present. Moreover, these effects are associated with limited changes in the average bank debt share of young or old firms.

We also examine the composition of borrowing across bank debt and non-bank debt and find economically large increases in the relative importance of bank debt for high-productivity firms. In contrast, these results are not associated with increases in the relative importance of non-bank debt for these same firms. This suggests that the previous increase in the relative use of bank debt by high-productivity firms is not explained by credit demand. Additionally, we also show that improvements in local economic conditions that are unrelated to local banking deregulation do not predict the previous patterns in the composition of firms' debt financing. These financial results provide direct evidence that our growth effects are matched with a significant shift in the composition of bank credit supply towards more productive firms. Both of these effects are only important among young firms and their estimated magnitudes are consistent with the view that the shift in credit supply drives the growth effects.

We conduct additional tests to further mitigate the possibility that deregulation might explain the growth effects through alternative mechanisms that differentially affect the growth of young, high-productivity firms. We note that deregulation is positively associated with local economic growth (Jayaratne and Strahan (1996)) and examine the effect of exogenous shocks positively affecting local economic conditions. We test if such shocks also lead to an increase in the relative growth of high-productivity firms which is differentially important for young firms. We examine shocks to overall state economic conditions but also consider shocks to subsets of local industries. Specifically, we consider the potential role of local demand effects by examining shocks to other local industries that are significant customers. Our results show that these local demand effects do 
not explain our growth results. ${ }^{7}$ We also analyze potential effects through local input markets and local labor markets. Across a range of such falsification tests, we provide direct evidence that leading alternative mechanisms cannot explain our growth results.

As a last step in our analysis, we examine the implications of our results for aggregate industry productivity. In order to guide this analysis, we use a simple monopolistic competition framework which has been studied in recent research connecting resource misallocation to industry productivity (e.g. Hsieh and Klenow (2009, 2014)). We focus on the implications of the previous change in the composition of credit supply in such a setting. We illustrate how these implications depend on how greater access to credit reduces firms' cost of using capital or labor. While models of finance and misallocation typically assume financial frictions only increase firms' cost of using capital, we discuss how recent empirical research on finance and labor implies that these frictions should also increase firms' cost of using labor. ${ }^{8}$ These labor effects can be more important than capital effects in increasing industry productivity because of the larger share of labor in production.

\footnotetext{
${ }^{7}$ Mian, Sufi, and Verner (2017) provide evidence that deregulation leads to local demand effects on employment which are only important in non-tradable sectors (outside of manufacturing). In contrast, with such effects, our analysis focuses on a mechanism through which deregulation can induce longer-term productivity gains.

${ }^{8}$ For example, recent evidence suggests that labor can increase the cost of financial distress by inducing operating leverage due to labor-market frictions such as firing costs (Serfling (2016)) and labor protection (Simintzi, Vig, and Volpin (2015)). Similarly, labor-market frictions and firm-specific training might make it costly for firms to fire workers in response to financial conditions. Other research suggests that financial distress might expose workers to significant costs and firms might need to compensate workers upfront for taking such risks, increasing firms' cost of using labor (Agrawal and Matsa (2013), and Graham et al. (2016)). All these ideas imply that finance affects the cost of using labor. See Moll (2014) and the references therein for models of finance and misallocation and Section 5 for more details on this issue.
} 
Specifically, we examine if deregulation leads to a significant convergence in the marginal revenue products of young firms with high versus low productivity. Our framework highlights how this convergence should only be present for labor if labor misallocation effects are important. We find that deregulation is associated with a significant convergence in the labor marginal revenue product gap of young firms with different productivity and that this pattern is similar for capital.

We then use our framework to quantify the magnitude of the implied gains in industry productivity and consider the role of labor in determining them. We take into account the fact that our results are concentrated on a subset of young firms and consider the implications of deregulations across all states for the aggregate productivity of a given industry. We find that our results imply gains between $1.1 \%$ and $2.1 \%$ of industry value added over a few years. This effect is equivalent to an increase between $3.3 \%$ and $6.2 \%$ in the output of the small young firms driving our results. We also find that labor misallocation plays a central role in determining these gains because of the larger share of labor in production.

Overall, our paper makes three main contributions. First, we provide direct evidence that the deregulation of U.S. state baking markets leads to a significant reallocation of resources towards young, more productive firms with economically important gains in aggregate industry productivity. Second, we provide evidence that these effects are driven by a shift in the allocation of bank credit towards high-productivity firms. This documents a specific mechanism through which the competition of local banking markets can matter for aggregate productivity. Finally, we 
also provide evidence that the allocation of labor, not only of capital, can play a central role in determining the quantitative implications of finance for aggregate productivity. ${ }^{9}$

In addition to previous research on U.S. banking deregulation, our analysis complements studies on the cross-country connection between financial development and the allocation of capital across industries (Wurgler (2000)) and on changes in this allocation within U.S. industries over time (Lee, Shin, and Stulz (2016)). It also complements studies which examine how countrylevel reforms in banking or financial markets matter for the allocation of resources (Bertrand, Schoar, and Thesmar (2006), and Larrain and Stumpner (2016)). Our study is the first to examine how micro-level changes in the composition of bank lending affect capital and labor reallocation and industry productivity.

\section{State Banking Deregulation}

\section{A. Background and Banking Deregulation Index}

Prior to the 1970 s most U.S. states had restrictions on banks' ability to operate within and across state borders that had remained historically stable. Given that small U.S. firms mostly relied on geographically close banks as a source of external financing until the early 1990s (Petersen and Rajan (2002)), these restrictions created local banking monopolies. Between the early 1970s and early 1990s, states relaxed these restrictions in a staggered way. Following previous research on U.S. state banking deregulation, we focus on two main types of restrictions imposed by states. First, states imposed restrictions on intrastate branching. For example, these included restrictions

\footnotetext{
${ }^{9}$ Previous research has examined the impact of finance on firm and aggregate employment (Benmelech et al. (2011), Pagano and Pica (2012), and Chodorow-Reich (2014)), but has not examined the impact of finance on aggregate productivity through the allocation of labor.
} 
on the ability of multibank holding companies to convert branches of acquired subsidiary banks into branches of a single bank, as well as restrictions on banks' ability to open new branches. As in Jaraytane and Strahan (1996), we choose the date of intrastate deregulation as the date in which a state permits branching through mergers and acquisitions.

Second, the Douglas amendment to the Bank Holding Act of 1956 prevented a bank holding company from acquiring banks in another state unless that state explicitly permitted such acquisitions by statute. No state allowed such acquisitions until the late 1970s. States then entered reciprocal regional or national arrangements which allowed their banks to be acquired by banks in any other state in the arrangement. Except for Hawaii, all states had entered such agreements in 1993. These episodes of interstate deregulation culminated with the passage of the 1994 RiegleNeal Interstate Banking and Branching Efficiency Act, which codified these state-level changes at the national level. Our data is available from 1977 and, motivated by the above timeline, we end our sample in 1993. We follow Amel (1993) and Kroszner and Strahan (1999, hereafter KS) in determining the dates of interstate and intrastate deregulation.

(Insert Figure 1 here)

We construct a state-level banking deregulation index (Dereg) by combining these two events which affected states during a similar period of time. Dereg is the sum of Intrastate_Dereg and Interstate_Dereg. Intrastate_Dereg and Interstate_Dereg are indicators that equal one if the state has passed intrastate and interstate banking deregulation, respectively. We show the dates for each of these events across individual states in Table IA.1. Figure 1 shows the average value across states of Interstate_Dereg, Intrastate_Dereg, and Dereg during each year of our sample period. The figure shows the significant deregulation wave that took place around the middle of the 1980s. 
KS argue that technological changes such as the development of more sophisticated credit-scoring models made it more difficult for local interest groups to protect local banking monopolies.

\section{B. How Does Banking Deregulation Matter?}

Previous research has documented that state banking deregulation is associated with local economic growth and has argued that changes in the composition of bank credit supply appears to be the channel driving such effect (Jayaratne and Strahan (1996, hereafter JS)). JS argue that deregulation might trigger a shift in the composition of bank lending towards higher-quality borrowers, which then increases the share of total investment coming from firms with better growth opportunities (composition effect). They conjecture that such changes in the allocation of bank credit might come from improvements in the screening and monitoring of the average local bank. Their evidence suggests that deregulation in a given state is not associated with significant increases in the aggregate loan growth in that state. At the same time, deregulation is associated with reductions in the aggregate importance of non-performing loans or charge-offs for banks in deregulated states. Jayaratne and Strahan (1998) find that most of this state-level drop in loan losses can be explained by the fact that better-performing banks increase their market share in a state after deregulation. This evidence is consistent with the idea that deregulation improves the composition of local bank lending by creating a stronger selection mechanism for local banks.

However, these studies do not provide direct micro-level evidence on the importance of the bank credit composition effect. Providing such evidence is important for at least two broad reasons. First, banking deregulation could explain the previous broad patterns through multiple economic channels, which could have different implications for when and how local banking competition matters. Improvements in the efficiency of local banks could lower their costs and translate into lower interest rates for all firms, reducing implicit barriers to entry, and facilitating the entry of 
new nonfinancial firms displacing less efficient incumbents. ${ }^{10}$ Second, evidence on the channel through which deregulation matters can also help to better establish its importance. ${ }^{11}$

We examine how deregulation affects the relative growth of high productivity firms. Our focus on differences in firm productivity within an industry is motivated by previous empirical and theoretical work on industry productivity and resource misallocation. ${ }^{12}$ Analyzing the previous composition effect requires firm-level data linking differences in firm productivity to their real and financial decisions. Moreover, since local banks should mostly matter for small firms, it is important to have micro-level data covering such firms.

\section{Data and Summary Statistics}

Our main data sources are the Longitudinal Business Database $(L B D)$, the Census of Manufacturers (CM), and the Quarterly Financial Reports (QFR) from the U.S. Census Bureau. The CM provides information on the sales and inputs used by all manufacturing firms every five years (i.e., Census years). Our analysis tracks changes in the relative growth of more productive firms around deregulation events and higher frequency data on small firms is useful to estimate these effects. Note that many deregulation episodes happen between Census years and higher

\footnotetext{
${ }^{10}$ Consistent with this view, Jayaratne and Strahan (1998) find that deregulation is associated with a drop in average interest rate in loans for local borrowers. The reduced demand for credit by large incumbent firms could offset some of the increase in borrowing by new firms.

${ }^{11}$ Huang (2008) argues that U.S. state deregulation leads to an acceleration of local growth only in a limited number of cases. Zarutskie (2006) provides evidence suggesting that local young firms use less bank debt after deregulation, while the opposite takes place for older firms. Since young firms are likely to be more constrained than older firms, this composition effect could lead deregulation to reduce aggregate productivity.

${ }^{12}$ For example, see Olley and Pakes (1996), Hsieh and Klenow (2009), Bartelsman, Haltiwanger, and Scarpeta (2013)), and the references therein. See Section 5 for more details.
} 
frequency data allows us to precisely analyze how a given firm changes around such events. We address this challenge by combining the CM with the LBD. The LBD provides annual employment information for every private establishment from 1976 onward. The underlying data are sourced from U.S. tax records and Census Bureau surveys. We use the LBD to annually track withinindustry differences in firm employment growth and link to the CM to relate these differences to firm productivity. We construct the main sample of data used in our growth results by matching firms in the LBD and the last available CM.

We focus on firms with their operations concentrated in a single state. State banking deregulation should matter mostly for firms with a strong geographic exposure to banks in the deregulated state. We also focus our analysis on firms that operate in a single industry. We need to compare the overall productivity of different firms operating in a given industry and this is challenging when firms also operate in other industries. Once we impose these two restrictions, almost all firms in our data are single-plant firms, which is the focus of our analysis. Overall, across all manufacturing firms in the LBD or the CM over our sample period, we find that 76\%77\% of establishments belong to single-plant firms. When we consider the total number of firms operating in a given industry and year (i.e., firm-industry-year observations), we find that $91 \%$ of firms are single-plant firms.

Our analysis examines differential patterns among young firms, which are plausibly more exposed to the effects that we want to isolate. We measure firms' age by considering the first year in which the firm appears with positive employment in the data. We construct age groups based on the difference between the current year and this first year of operations. Our main age groups are Young1 and Young2, which include firms present for the first time in the previous CM and present for the first time in the $\mathrm{CM}$ before the previous one, respectively. Old includes the 
remaining firms. ${ }^{13}$ These groups capture firms with age 1-5 and 6-10 in the previous CM, respectively. In our analysis, we focus on composition effects among these young firms with a single plant. While these firms represent a subset of the overall sample of firms in an industry, we explicitly take this into account when examining the implications of our results for aggregate industry productivity in Section V. ${ }^{14}$

\section{(Insert Table I here)}

Panel A of Table I shows summary statistics for this overall sample and subsamples of young firms. As described in Section I.A, our sample covers the period between 1977 and 1993. All variables are described in Appendix A. The average firm in our overall sample is small and has 22.3 workers and 1.4 Million in sales (\$1987). In some of our additional results of the real effects of deregulation, we restrict our analysis to Census years. This comes from the need to examine outcomes not covered in the LBD (e.g., capital stock growth) or a focus on longer-term effects of deregulation (e.g., analysis in Section V). In these results, we use only the CM to construct similar samples of single-plant firms in different age groups.

Our analysis of changes in firms' financial policies is based on the QFR. The QFR collects quarterly balance sheet and income statement data on large-, medium-, and small-size

\footnotetext{
${ }^{13}$ This basic approach to classify firms into an age group is used by Haltiwanger, Jarmin, and Miranda (2013) and the Census Bureau (e.g., https://www.census.gov/ces/dataproducts/bds/definitions.html). We use the CM to define our main age groups because the LBD only starts in 1976, and this limits our ability to construct different age groups at the start of our sample period (1977 to 1993). We use the CM data from 1967 onward and this allows us to have at most three age groups at the start of our sample (age 1-5, age 6-10, and age 11+). We also construct age groups using the LBD as a robustness check, but have to limit the sample period of our analysis in these results.

${ }^{14}$ Using the CM in our sample period, we have found that $56 \%$ of firms that operate in a given industry are singleplant firms with an age between 1 and 10 years.
} 
manufacturing corporations. This data is available for us at the firm-level during Census years, and we construct annual firm-level values for the variables in these years using averages for each firm. We construct our sample for this analysis by matching the QFR (with annual values) and the $\mathrm{CM}$ in Census years. As before, we only include single-plant firms. We also note that the QFR uses a random sample of firms, different from the population of firms in the CM and LBD. We construct sample weights based on firm size and age that replicate the importance of size and age groups in our previous sample described in Panel A. We estimate results with these weights, which allows us to estimate effects that are representative of the same sample considered in our analysis of real effects. This sample includes firms in 1977, 1982, 1987, and 1992.

Panel B of Table I describes the main variables used in this analysis. We report summary statistics with the sample weights used in the results. We focus on variables which capture the importance of bank debt and non-bank debt financing. Companies separately report their debt from commercial banks (bank debt) and other sources in the QFR. We measure the importance of bank debt using the ratio of bank debt to total debt (Bank Debt Share). We also separately measure the ratios of bank debt and non-bank debt to total assets, which we label Bank Debt Ratio and NonBank Debt Ratio, respectively. This distinction is important in our analysis because only commercial banks are directly affected by banking deregulation. Between 40\%-50\% of firms’ debt comes from non-bank sources for both young and old firms. This shows that firms significantly rely on both bank and non-bank debt. Additionally, the combination of firms' bank and non-bank debt represents approximately 30\% of firms’ assets, and this ratio is significantly larger for young firms where this combination represents approximately $40 \%$ of firms' total assets. This suggests that the young single-plant firms in our analysis significantly rely on debt financing. These values 
do not include trade credit and are similar to the ones described in Petersen and Rajan (1994) based on the National Survey of Small Business Finances (NSSBF) for the late 1980s. ${ }^{15}$

As discussed in Section I.B, an important variable in our analysis is firm total factor productivity (TFP). We include measures of firm TFP using data from the CM. Following previous research in finance examining productivity, we follow a simple strategy to estimate plantlevel TFP. We estimate a Cobb-Douglas production function with separate parameters for each industry-year (3-digit SIC code). We estimate these parameters using ordinary least squares (OLS) with year fixed effects and data from the previous five years. ${ }^{16}$ As a robustness check, we report our main credit composition and labor reallocation results using alternative approaches for estimating TFP in Table IA.2 and Table IA.3, respectively. Since we focus on single-plant firms, our measures of firm productivity are the same as plant productivity.

\footnotetext{
${ }^{15}$ The NSSBF provides information on the main sources of non-bank debt for small businesses, which are non-bank financial institutions, the company owner, and the family of the owner. When compared to the NSSBF, there are fundamental advantages of using the QFR for our purposes. The NSSBF only starts in 1987, what limits one’s ability to analyze the effect of banking deregulation in our sample period (1977-1993). Additionally, the QFR provides a significantly larger and more comprehensive sample of manufacturing firms which can be matched at the firm-level to measures of productivity based on plant-level data from the CM.

${ }^{16}$ Annual plant-level data from the Annual Survey of Manufacturers (ASM) for a subsample of plants is used to estimate production function parameters, which are then combined with the CM to measure plant-level TFP for all firms in our samples in Census years. Appendix A describes this approach and robustness in greater detail. Recent research in finance using similar measures of firm productivity include Maksimovic, Phillips, and Yang (2013), Krishnan, Nandy and Puri (2014), and Giroud and Mueller (2015).
} 


\section{Banking Deregulation and Labor and Capital Reallocation}

We start our analysis by examining how the relative growth of high-productivity firms changes after deregulation. We separately analyze this effect within different age groups and focus on the differential effect for young firms. By examining immediate changes to young firms around deregulation and comparing them to other young firms in states that did not deregulate in that year, we can better isolate the effect of these events from other changes affecting industries in a given state. This higher-frequency analysis is important for comparing a firm before and after deregulation.

We analyze these growth effects by estimating the equation:

$$
\begin{aligned}
\text { EmpGrowth }_{i s j t}= & \alpha_{s j t}+\mu_{i}+\gamma_{s} \times T F P_{i s j t}+\theta_{t} \times T F P_{i s j t} \\
& +\beta \times \text { Dereg }_{s t} \times T F P_{i s j t}+\delta^{\prime} X_{i s j t}+\varepsilon_{i s j t}
\end{aligned}
$$

where EmpGrowth ${ }_{i s j t}$ is the employment growth of firm $i$ in industry $j$, state $s$ and year $t, \alpha_{s j t}$ is a state-industry-year fixed effect, $\mu_{i}$ denotes firm fixed effects, TFP is the firm's total factor productivity (in logs), $\theta_{t}$ denotes year fixed effects, $\gamma_{s}$ denotes state fixed effects, Dere $g$ is the banking deregulation index, and $X$ denotes controls. TFP is measured in the previous CM. Control variables include Large, Age1, Age2, and the interactions of each of these variables with the previous two deregulation indicators.

We separately estimate Equation (1) for different age groups (Young1, Young2, and Old) and examine the differential value of $\beta$ for young firms. In each age group, the estimation of $\beta$ examines how the sensitivity of firms' growth to their productivity (TFP) in a local industry relates to state banking deregulation. The increase in firm growth predicted by TFP captures the 
sensitivity of this growth to a given gap in firm productivity, which is measured within an industrystate-year because of the fixed effects.

Intuitively, one can think about this estimation as involving two steps. First, we estimate the previous sensitivity within each industry-state-year. We then estimate how deregulation affects this relationship using a difference-indifferences specification. We are implementing these two steps together in a single regression. ${ }^{17}$ Finally, when we contrast this estimated effect for different age groups, we are analyzing a triple difference, which tells us the differential change in the previous sensitivity for young firms. This last interaction allows us to contrast the effect of deregulation on different groups of firms in the affected states and control for broad changes around deregulation in the previous sensitivity of industries in affected states.

We initially focus on employment growth because this is an important outcome that can be measured at an annual frequency for a broad range of firms. Previous research has provided direct evidence that bank credit availability affects the employment of small and medium firms (e.g., Chodorow-Reich (2014)), so changes in the composition of credit should translate into shifts in relative employment growth. ${ }^{18}$ Table II reports these employment growth results. All reported coefficients are scaled to capture changes in the relative growth of firms in the top versus bottom

\footnotetext{
${ }^{17}$ Recall that TFP is measured in the previous CM. In our main age group of interest (Young1), this variable measures the first value of TFP in the data for the firm. This within-industry-state-age sensitivity is analogous to the withincountry sensitivities of industry investment to industry fundamentals such as $Q$ or value-added growth in Wurgler (2000) and Lee, Shin, and Stulz (2016). As discussed in Section 1.2, we focus on these differences in firm productivity because they have been emphasized as a fundamental determinant of aggregate industry productivity.

${ }^{18}$ As we discuss in greater detail in Section 5, this labor effect can be an indirect effect from a lower cost of using capital or a direct effect from greater credit availability on firms’ cost of using labor.
} 
quartiles of an industry-state. More precisely, we multiply the estimated coefficients by the average TFP gap between these two groups. We start by analyzing the average effect of deregulation across different age groups.

\section{(Insert Table II here)}

Column (1) of Panel A reports this result, which is based on the estimation of Equation (1) with additional controls: Young1, Young2, and their interactions with the two deregulation variables. This result shows that deregulation is associated with a significant average increase in the relative growth of high-productivity firms. This result implies that deregulation (i.e., change in Dereg between zero and two) is associated with an increase of $1.8 \%$ in the relative employment growth of firms in the top TFP quartile.

Column (2) of Panel A examines the differential effect for Young1. In this specification, all independent variables (including controls) and fixed effects in Equation (1) are included with and without their interaction with Young1. The only variables not interacted with Young1 are Age1 and Age2. Column (3) separately examines these differential effects for Young1 and Young2. This last result is based on an analogous specification where the independent variables and fixed effects are now separately interacted with Young1 and Young2. These results show that the previous effects are differentially stronger for the youngest firms and driven by these firms. There is an economically and statistically significant increase in the relative growth of more productive firms only among the youngest firms. The effect for older firms is economically small and statistically not significant in Column (1). This effect is negative in Column (2). The results imply that, in the subsample of young firms (Young1), deregulation is associated with a differential increase between $3.0 \%$ and $4.2 \%$ in the relative employment growth of the top TFP quartile. Recall from Table I that the average employment growth of these same young firms in the sample is 5.7\%. 
We next consider the possible role of firm age and size in explaining these results. One possibility is that differences in firm TFP are capturing these characteristics and the previous results reflect changes in the link between firm growth and age or size. In the context of age, we note that we are comparing only firms within a same age group and year. In our main group of interest (Young1), within-group-year differences in age are limited to five years. We also include continuous measures of firm age based on the LBD (Age1 and Age2) as controls. ${ }^{19}$ As an additional robustness check on the role of age differences, we estimate our previous results without these last controls. Columns (1) and (2) of Panel B of Table II report the estimated effects. The effects for the interaction with Young1 remain similar in the results with and without these controls. We also consider an alternative definition of Young1 using the LBD. Young1 is now an indicator that equals one if the firm has age between one and five years using the LBD, and can only be defined from 1982 on (see Section II). Column (3) of Panel B reports the results with this variable, which capture younger firms than Young1 in the previous specifications. The results become economically stronger with this alternative specification.

We next consider the role of size. We note that, in contrast with age, firms' size should be endogenously affected by their productivity as more productive firms should find it more attractive to expand their business. Indeed, previous models and evidence on resource allocation within industries have emphasized this idea and the existence of a strong positive link between size and productivity within an industry. In these frameworks, productivity is the exogenously given firm

\footnotetext{
${ }^{19}$ As discussed in Section 2, our main age groups are based on the CM. The LBD provides a more continuous measure of age, but the data starts in 1976, what limits our ability to construct broad groups of age with this data. We therefore construct these additional continuous controls. Also notice that, as previously discussed, all controls are interacted with the deregulation indicators.
} 
characteristic and conditioning on firms' choice of size while examining a link with productivity can bias our estimates. For this reason, in our main results we only use broad controls for firms' size group (Large). Large is an indicator that equals one if the firm is above the median size (employment) within the industry-age group-year. We examine how the results change as we exclude or add size controls. Columns (1) and (2) of Panel C (Table II) show the results without the previous size control. We then estimate the effects with narrower group sizes as controls. We include indicators for all size quintiles within an industry-age group-year, constructed in an analogous way to Large. Columns (3) and (4) of Panel C report these results. Across these sets of results, the effects remain similar and become economically stronger as we add more size controls. Together with the previous age analysis, these results show that the results in Table II are not capturing a change in the link between employment growth and size or age within local industries.

We check if our previous employment growth effects are matched with changes in the relative growth of firms' capital stock. If the previous results are driven by changes in the composition of bank credit, it is natural to expect them to be associated with capital effects. One challenge in implementing this analysis is that it is only in Census years that we can observe firms' capital stock growth for a broad range of small firms. This is especially relevant because we focus on young firms. In a sample only with Census years, firms in Young1 are present in the data for the first time and one cannot contrast their growth after deregulation with a previous growth outcome prior to this event. In Table III, we therefore estimate the same specification used in Table II (Columns (2) and (3) of Panel A) but exclude firm fixed effects.

(Insert Table III here) 
Table III shows that our previous effects are matched with an important increase in the relative capital growth of high-productivity firms in the sample of young firms. Deregulation is associated with an increase of $0.8 \%$ in the relative capital growth of the top TFP quartile for young firms.

Lastly, we examine the dynamics of the previous growth effects. We focus on employment growth because we can measure this outcome each year. We first consider if the previous changes in relative growth after deregulation are associated with pre-existing trends. These results are based on specifications that add more variables to the ones in Table II (Column (3) of Panel A). More specifically, we add Dereg(-1 to -3) or Dereg(-1 to -6) in an analogous way to Dereg and include the same set of interactions used for Dereg. These variables are constructed in the same way as Dereg using a sum of two indicators (for intrastate and interstate deregulation) that now equal one in the three or six years prior to deregulation events. Table IV reports these results.

(Insert Table IV here)

The results show that our previous effects are not associated with pre-existing positive trends in the relative growth of young firms with high productivity. This growth only changes after deregulation. We also analyze these changes in growth using narrower windows of time. We implement this by splitting our sample in three periods of time (1977 to 1982, 1983 to 1988, and 1989 to 1992) and separately estimating our previous effects in each of them. We then estimate an average effect across these periods. Notice that this effect can only be estimated by contrasting the period right after deregulation with the period right before this event. In addition, Table IA.4 provides evidence that our previous findings are robust to narrowing the window of time and focusing on immediate growth after the deregulation events.

\section{How Does Banking Deregulation Affect the Bank Credit Supply?}


We now examine the role of changes in the composition of bank lending in driving our differential growth effects for young, productive firms. In particular, we study whether there is a shift in the composition of bank credit supply towards more productive firms. We also analyze if the magnitude of these financial results is consistent with the view that they drive the previous real effects. We then conduct a series of robustness tests that consider the potential role of alternative mechanisms in driving the previous relative growth effects.

\section{A. Banking Deregulation and the Composition of Bank Lending}

We examine if the previous results showing differential higher growth for young, productive firms are associated with changes in the composition of bank credit supply. We separately examine different age groups to test if changes in the composition of bank credit are mostly important for young firms. We link firms' bank debt to their productivity for a broad range of firms, and weight these firms using sample weights to match our previous sample of single-plant firms.

A challenge for isolating credit supply effects is the fact that deregulation might also affect firms' demand for bank debt. We address this issue by examining how firms borrow across different sources of debt financing. Our data allows us to measure both bank debt (from commercial banks) and non-bank debt (from other sources). Only commercial banks are directly affected by state banking deregulation. ${ }^{20}$ We argue that changes in credit demand should affect firms’ demand for both bank and non-bank debt. In contrast, increases in bank credit supply should lead to an increase in the share of total debt coming from banks (bank debt share) for a given firmyear. As a first approach to isolate bank credit supply effects, we thus examine if deregulation is

\footnotetext{
${ }^{20}$ We show in Section 2 that bank debt represents between 50\%-60\% of firms' total debt for both young and old firms in our sample. Therefore, both sources of debt financing are important. As discussed in Section 2, these numbers are similar to the ones found in previous research using small business surveys (Petersen and Rajan (1994))).
} 
associated with a more positive link between firms' productivity and their bank debt share. This basic approach to isolate shifts in bank credit supply using the share of bank debt is also used in Kashyap, Stein, and Wilcox (1993) and Becker and Ivashina (2014).

The financial data we use is only available in Census years (CM conducted every five years). We therefore focus on longer-term effects of deregulation and explore the fact that there is a big national-level deregulation wave between the middle and end of the 1980s (see Figure 1 and Section I.B for a discussion). At the start of our sample (1977), approximately one third of states had (partially) deregulated their local banking markets and this initially determined set of states (initially deregulated) should be less affected by the subsequent deregulation wave. The wave should lead to a convergence of the deregulation status of initially different states. We compare the link between firms' bank debt share and their productivity across initially deregulated states and other states in a same year. We examine if this difference across states is more positive prior to the wave. We implement this idea by estimating the following specification:

$$
\begin{aligned}
\text { BankDShare }_{i s j t}= & \alpha_{s j t}+\gamma_{0} \times I \text { Dereg }_{s} \times \text { TFP }_{i s j t}+\gamma_{1} \times \text { Pre }_{t} \times T F P_{i s j t} \\
& +\beta \times \text { IDereg }_{s} \times \text { Pre }_{t} \times T F P_{i s j t}+\delta^{\prime} X_{i s j t}+\varepsilon_{i s j t},
\end{aligned}
$$

where BankDShare is the ratio of firms' bank debt to total debt (bank and non-bank debt), IDereg is the value of Dereg in a state at the start of the sample period (1977), Pre is an indicator that equals one in the years prior to the deregulation wave (1977 and 1982), $X$ denotes controls, and all other variables are defined in the same way as in Equation (1). Control variables include Large, indicators for age groups, and the interactions of each of these variables with Pre, IDereg, and Pre $\times$ IDereg. Age groups are constructed based on the number of years since the firm first appeared in the CM (Age 1-5, Age 6-10, and Age 11+). We separately estimate this specification for different age groups and, in each age group, focus on the estimation of $\beta$. 
In an analogous way to our previous analysis, the estimation of $\beta$ within each age group can be interpreted as difference-in-differences approach where the outcome variable is the link between firms' bank debt share and their productivity. We analyze if the difference in this link between initially deregulated states and other states is more positive prior to the deregulation wave. Our data covers years 1977, 1982, 1987, and 1992, and that this wave takes place in the middle of this period (see Figure 1). Also notice that, when compared to our previous results, this estimation includes one additional level of contrast (bank debt versus non-bank debt).

\section{(Insert Table V here)}

Panel A of Table V reports the results for different age groups. To make the results comparable to previous tables, we multiply the estimated effects by the gap in TFP between the top and bottom quartiles of an industry-state. The results show that deregulation is associated with an economically and statistically more positive link between firms' bank debt share and their productivity for young firms. This effect is also positive for old firms (age 11+) but only statistically significant for young firms. The economic magnitude of this effect for old firms is approximately eight times smaller than the one for the youngest firms (age 1-5). Moreover, this magnitude for young firms is important in absolute terms. The interaction $I$ Dereg $g_{s} \times$ Pre $_{t}$ captures a gap in Dereg of approximately 1.0.

The effect for young firms (age 1 -10) implies that deregulation (i.e., a change in Dereg from zero to two) leads to an increase of 0.41 in the relative bank debt share of top TFP firms. Note that this is a relative effect. In the absence of significant changes in the average value of firms' bank debt share (see below), this estimate implies effects with the opposite sign and half of this magnitude for top and bottom TFP firms. Note that the mean value of this bank debt share is around 0.55 for these same young firms (Table I). 
We further analyze these differences across age groups by estimating the differential value of the previous effects for young firms. Panel B of Table V reports these differential values, which are statistically significant and economically similar to the previous estimates for young firms. This similarity is expected given the small (relative) magnitude of the effect for the old group.

(Insert Figure 2 here)

Figure 2 examines the dynamics of these effects. We report results analogous to the previous ones (Panels A and B of Table V) with effects that are separately estimated across different years (1977, 1982, and 1987). Figure 1 suggests that the deregulation wave becomes strong between 1982 and 1987. Figure 2 shows that the previous convergence effects mostly take during this same period and among young firms. This provides additional evidence that the previous financial patterns capture banking deregulation.

As an alternative approach, we also estimate these effects with following specification:

$$
\begin{aligned}
\text { BankDShare }_{i s j t}= & \alpha_{s j t}+\theta_{t} \times T F P_{i s j t} \\
& +\beta \times \text { Dereg }_{s t} \times T F P_{i s j t}+\delta^{\prime} X_{i s j t}+\varepsilon_{i s j t},
\end{aligned}
$$

where all variables are defined in the same way as in Equations (1) and (2). The control variables $(X)$ include Large, indicators for age groups, and the interactions of each of these variables with Dereg. This specification compares the link between firms' bank debt share and productivity across states with different deregulation status at a same point in time. We also separately estimate this specification for different age groups. ${ }^{21}$ The main advantage of including this alternative

\footnotetext{
${ }^{21}$ Notice that the addition of $\gamma_{s} \times T F P_{i s j t}$ as a control would lead $\beta$ to be estimated for each age group with differencein-differences approach analogous to the one in Equation (2). However, our sample size for young firms in these financial results is more limited and the inclusion of all these fixed effects is demanding. When we included all these fixed effects, we have found similar point estimates but large standard errors that do not allow us to statistically detect
} 
specification is that it uses broader variation on deregulation to estimate the previous effects. The main disadvantage is that it relies only on cross-sectional differences in deregulation.

Panel C of Table V reports the results with this alternative specification. Since the previous interaction $I$ Dereg $g_{s} \times$ Pre $_{t}$ captures a gap in Dereg of approximately 1.0, the magnitude of these results is directly comparable to the ones in Panel A. The effects remain qualitatively and quantitatively similar to those previously estimated. Panel D of Table V then considers if these relative changes in the importance of bank debt for more productive firms are associated with significant changes in the average importance of bank debt. We rely on the same interaction IDereg $_{s} \times$ Pre $_{t}$ used in Panel A but now analyze average changes on BankDShare, as opposed to the relative effects for high-productivity firms. The results show that these average changes in the share of bank debt are economically limited and statistically insignificant. These results suggest that deregulation mostly affects the composition of credit in each of these age groups, consistent with the previous evidence on banking deregulation discussed in Section I.B.

One concern with these results is that deregulation could potentially affect the relative demand by firms for bank debt versus non-bank debt. We examine this possibility by separately analyzing changes in these two sources of debt financing. We argue that it is challenging to imagine that high-productivity firms would only increase their demand for bank debt in response to deregulation. Therefore, if the results are driven by increases in the credit demand, rather than credit supply, for these firms, they should plausibly be associated with increases in both bank and non-bank debt. Table VI reports results with the same specifications used in Table V with both

effects with the magnitudes here considered. In Section 5, we analyze this same specification with a broader sample (different outcome) and show that the inclusion of this additional control does not significantly affect the results. 
Bank Debt Ratio and Non-Bank Debt Ratio as the outcome variables. These results show that the previous effects among young firms are matched with an economically and statistically significant increase in the relative importance of bank debt (level) for high-productivity firms but a statistically insignificant and economically much smaller drop in the importance of non-bank debt - consistent with credit supply changes and not credit demand driving the results. These patterns are once again robust across specifications and are not present for old firms. ${ }^{22}$

\section{(Insert Table VI here)}

We also address the concern that it might be credit demand rather than credit supply that is responsible for the results with an additional falsification test. We consider if economic shocks affecting a state also lead to the previous patterns on the link between firms' bank debt share and their productivity. More specifically, we estimate specifications analogous to the ones in Table V which replace IDereg with Shock, which capture state-level economic shocks during our sample, and replace Pre with Post $=1$-Pre. Table VII reports the results. We first define Shock as a predicted shock to state economic conditions between 1977 and 1993, constructed by combining the initial (employment) composition of industries in each state with the realized national-level (employment) growth of different industries over the same period. ${ }^{23}$ This captures exogenous

\footnotetext{
${ }^{22}$ If deregulation changes local economic conditions in such a way that it strongly increases firms’ preference for bank debt over non-bank debt, in principle, a strong substitution away from non-bank debt could lead to such patterns. We further address this possibility below and also notice that typical models of financial intermediation predict that improvements in economic conditions are associated with a reduced preference for bank loans relative to other sources of debt (e.g., Holmstrom and Tirole (1997)).

${ }^{23}$ The predicted shock is the weighted average of national-level shocks to industries based on initial weights (see Appendix A for more details). Intuitively, states are differentially affected because they rely on industries experiencing heterogeneous national-level shocks. This approach to predict local economic shocks was proposed by Bartik (1991)
} 
shocks to state-level conditions. We also define Shock as the state's employment growth between 1977 and 1992, and control for the effect of deregulation in this analysis. This captures broad changes in state economic conditions not associated with banking deregulation. In both cases we find evidence that improvements in state economic conditions are not associated with the previous patterns on firms' bank debt share.

\section{(Insert Table VII here)}

Finally, we consider whether the magnitude of these financial results for young firms is consistent with the view that they drive the previous growth effects. The result for young firms in Panel A of Table VI implies an increase of $14 \%$ in the relative bank debt ratio of the top TFP quartile. This relative bank debt increase is equivalent to $14 \%$ of firms' total assets after a change of 1.0 in Dereg and over a period of approximately five years. The previous employment growth effects for young firms (Table II) imply increases in relative employment between $7.0 \%$ and $10.0 \%$ over five years. These magnitudes suggest that the financial results can plausibly explain our previous growth results.

\section{B. Alternative Mechanisms}

Our previous analysis provides direct evidence that the reallocation results are matched with a significant shift in the composition of bank credit supply towards young, more productive firms. We now analyze in greater detail whether other economic mechanisms could also explain our previous reallocation results. At a broad level, firms could be indirectly affected by deregulation through changes in local economic conditions, in addition to being directly affected by the

and Blanchard and Katz (1992) and is commonly used in economics (e.g., Autor and Duggan (2003)), as well as has been recently used in finance (Adelino, Ma, and Robinson (2016)). 
previously documented changes in bank lending. Deregulation might affect the entry of new local firms, as well as the decisions of local consumers or other local firms. This can then change the economic conditions faced by a given existing firm after deregulation.

For example, one possibility is that deregulation might increase the contestability of local product markets for nonfinancial firms. This could increase the incentives for incumbents to maximize their value, increasing the alignment of firms' decisions with their productivity. Alternatively, new firm entry or the expansion by other existing firms could drive up prices for local inputs or labor. Less productive firms might be more exposed to such local price increases, which could trigger a reallocation of resources towards more productive firms.

We note that, in order to explain our reallocation results, these alternative mechanisms need to generate an increase in the relative growth of more productive firms which is only present among young firms. Some of these effects, such as increases in product market contestability, should naturally affect older incumbent firms. Moreover, in some examples such as local demand effects, it is also unclear if changes in these conditions would differentially affect more productive firms. However, one might be concerned that older firms are larger and have a limited sensitivity to local economic conditions. If some changes in local economic conditions increase the relative growth of high-productivity firms, the limited sensitivity of older firms could lead these effects to be only relevant for young firms. In contrast to this view, previous research in our setting has provided direct evidence that the growth of both existing young and old firms are significantly responsive to local economic conditions (Adelino, Ma, and Robinson (2016)). This research has found comparable sensitivities to local economic conditions across these two groups. We also note that 
our analysis focuses on single-plant firms and that the older firms in our analysis are mostly small firms, with an average employment equal to 29 workers (see Table I). ${ }^{24}$

We further address this concern in two main ways. First, we build on our previous financial policy results. These alternative channels predict that the increase in the relative growth of highproductivity firms should be associated with a relative increase in the credit demand of these same firms. In these alternative mechanisms, the increase in the relative growth of high-productivity firms is not driven by the direct effect of greater access to bank credit at the firm level. In contrast with the view that these channels drive our results, our analysis in Section IV.A suggests that deregulation is not associated with an increase in the relative credit demand of firms with high productivity among young firms.

We then also address this concern with a new intuitive falsification test. This analysis directly checks if leading alternative mechanisms can generate the patterns in our previous growth results. More specifically, we examine if positive shocks to local economic conditions generate an increase in the relative growth of high-productivity firms that is differentially more important for young firms. Recall that deregulation is positively associated with local economic growth (Jayaratne and Strahan (1996)). We consider both broad shocks to state economic conditions as well narrower shocks that focus on specific alternative mechanisms such as increases in the local demand for an industry's products.

\section{(Insert Table VIII here)}

Table VIII reports these results. These results are based on the estimation of a specification analogous to the one analyzed in Table II (Columns (2) and (3) of Panel A), which replaces Dereg

\footnotetext{
${ }^{24}$ In non-reported results, we have also found that this contrast between the effects for young and old firms remains similar if we only contrast firms within a same size group.
} 
with Shock. The results include the same set of controls as in Table II, which are now defined in analogous ways using Shock. The different panels are based on different definitions for Shock. We here describe the basic idea for these definitions and provide more details in Appendix A. We first define Shock with the two basic approaches used in Table VII to capture shifts in state-wide economic conditions. In Panel A, Shock is a predicted shock to state economic growth between 1977 and the current year. This shock is constructed by combining the initial (employment) composition of industries in each state with the realized national-level (employment) growth of different industries over the period (1977-current year). The predicted shock is the weighted average of national-level shocks to industries based on initial weights. This captures exogenous shifts to state economic conditions triggered by national-level changes to its industries.

In Panel B, Shock is the state's employment growth between 1977 and the current year. These results include Dereg and all its interactions used in Table II as additional control variables, and capture shifts in state economic conditions that are not associated with state banking deregulation. As in our previous results, we scale the estimated effects by multiplying them by the TFP gap between the top and bottom quartiles of an industry-state. In order to better capture the magnitude of effects, we also multiply these estimates by the standard deviation of Shock in the sample being analyzed. ${ }^{25}$ The results presented in Table VIII show that positive changes to state-wide economic conditions do not lead to our previously shown growth results. The magnitude of the estimated effects across all specifications is limited when compared to the ones in Table II. Moreover, in the

\footnotetext{
${ }^{25}$ Notice from Table 1 that multiplying the effects in Table II by the standard deviation of Dereg would not significantly affect our reported estimates.
} 
cases where the effects are economically stronger or statistically significant, they all have the opposite sign of our growth results.

After considering the role of broad changes to state economic conditions, we focus on specific alternative channels. In these results, Shock is a predicted shock to the growth of a subset of other connected industries in the same state between 1977 and the current year. The shock to this subset of connected industries is predicted in an analogous way to the approach used in Panel A (using national-level shocks). Intuitively, positive shocks to local connected industries take place when these same industries are growing faster at the national level. We follow Ellison, Glaeser, and Kerr (2010) in the definition of connections, which are all defined at the national level and described in greater detail in Appendix A. ${ }^{26}$

Panel C considers if positive shocks to local demand conditions predict the patterns in our growth results. This analysis is motivated by the possibility that deregulation leads to increases in the local demand faced by industries, which then generate the previous growth patterns. For each industry $i$, we use input-output tables to classify industry $j$ as a buyer if it purchases a sufficiently large share of the sales from industry $i$. This share is calculated using all customers, including final customers. We then capture demand shocks to an industry-state by predicting shocks to its local buyers (in the same state). The results in Panel C show that these positive shocks to local demand are statistically insignificant and do not explain our results.

\footnotetext{
${ }^{26}$ The evidence in Ellison, Glaeser, and Kerr (2010) suggests that these measures of connections across industries empirically capture interactions in product, input, and labor markets. In non-reported results, we have found similar results when we followed the approach in Panel B and used measures of realized growth for connected industries that are not associated with deregulation.
} 
Panels D and E consider changes in local input markets and labor markets, respectively. These analyses address the previously discussed possibilities that positive shocks to the local demand for industries' inputs or labor could lead to the patterns in the growth results. In Panel D, we use inputoutput tables to classify industry $j$ as a supplier for industry $i$ if an important share of the inputs

used by industry $i$ comes from industry $j$. This share is calculated using all suppliers. Positive shocks to the local input markets of an industry-state are then defined as shocks to its suppliers in the same state. In Panel E, for each industry $i$, we classify industry $j$ as a common labor industry if both industry $i$ and $j$ use workers in similar types of occupation. In an analogous way to the previous approaches, positive shocks to the local labor markets of an industry-state are predicted shocks to common labor industries in the same state.

The results in Panels D and E show that positive shocks to input and labor markets are also insignificant and do not generate the patterns in the previous growth results. The economic magnitude of all these effects is limited when compared to the ones reported in Table II. While it is challenging to completely rule out the role of alternative mechanisms in driving our results, our evidence is mostly consistent with the view that our growth effects are explained by the effect of deregulation on the composition of credit supply among young firms.

\section{Implications for Industry Productivity}

We now examine the implications of the previous reallocation effects for industry productivity. In order to guide our analysis, we use a simple model of monopolistic competition with heterogeneous firms, which has been studied in recent research connecting resource misallocation to industry productivity (Hsieh and Klenow $(2009,2014)$ ). We consider the role of the composition of bank credit supply into this model. 
We first use this framework to motivate simple tests for the hypothesis that our previous results lead to industry productivity gains. We solve for an expression that captures local misallocation losses by different groups of firms by industry and state, following our empirical analysis. We then use it to quantify the implied magnitude of these gains from changes to bank credit supply through bank deregulation.

\section{A. Theoretical Framework}

We present the model's set up and discuss the intuition for its main results. Appendix B shows the formal steps for these results. The model considers an industry $j$ where $N_{j t}$ firms produce differentiated products at time $t$ and are monopolistic competitors with Cobb-Douglas production functions. More specifically, the (real) output for firm $i$ is given by:

$$
Q_{i j t}=A_{i j t}\left(K_{i j t}\right)^{\alpha_{j}}\left(L_{i j t}\right)^{\beta_{j}}\left(M_{i j t}\right)^{\gamma_{j}},
$$

where $A_{i j t}$ is a firm-specific productivity component, $K_{i j t}$ is the firm's capital stock, $L_{i j t}$ denotes the labor used by the firm, and $M_{i j t}$ is the firm's choice of materials. Firms face constant returns to scale on their technology $\left(\alpha_{j}+\beta_{j}+\gamma_{j}=1\right)$ but their revenue function has decreasing returns to scale because of the downward-slopping demand for their products. We assign each firm $i$ to a primary state $s$ and to a unique group $g$ by industry-state. We interpret these groups as capturing the samples of local young and old single-plant firms, as well as remaining firms, in an industrystate from our empirical analysis. We assume that firms in the industry face exogenously given factor prices that might depend on their state.

Firms in the industry supply their output to a representative firm producing industry output:

$$
Q_{j t}=\left(\sum_{i=1}^{N_{j}} Q_{i j t}^{\frac{\sigma-1}{\sigma}}\right)^{\frac{\sigma}{\sigma-1}}
$$


This representative firm sells its output (industry output) in a perfectly competitive market at a price $P_{j t}$. These assumptions allow us to determine the demand for the differentiated products in the industry and lead to a constant elasticity of demand for these products.

This setting allows us to express industry output as $Q_{j t}=T F P_{j t}\left(K_{j t}\right)^{\alpha_{j}}\left(L_{j t}\right)^{\beta_{j}}\left(M_{j t}\right)^{\gamma_{j}}$, where $T F P_{j t}$ is industry productivity, $K_{j t} \equiv \sum_{i=1}^{N_{j}} K_{i j t}$ is the industry's capital, and $L_{j t}$ and $M_{j t}$ are the industry's labor and materials, respectively. Industry productivity changes when the industry produces more output with the same aggregate inputs. This will happen if individual firms become more productive or if the same aggregate industry inputs are used by more efficient firms. The allocation of resources is defined in broad terms and captures the distribution of factor shares across firms. ${ }^{27}$ Conditional on a set of firms and their productivity distribution, industry productivity will be maximized when resources are reallocated across firms to equalize marginal revenue products. ${ }^{28}$

We allow for firms to be potentially exposed to firm-specific frictions affecting their cost of using capital and labor, which can lead to gaps in their marginal revenue products of firms and induce losses in industry productivity. Firms choose their inputs to maximize current profits, subject to these distortions. These profits are given by:

\footnotetext{
${ }^{27}$ This broad definition of resource allocation is commonly used in studies of industry productivity (e.g., Olley and Pakes (1996)).

${ }^{28}$ The prices of differentiated products can be used to evaluate their marginal contributions to industry output. Industry productivity will be increased by reallocating factor $F$ from firm $i$ to firm $k$ if $p_{k t} \frac{\partial Q_{k t}}{\partial F}>p_{i t} \frac{\partial Q_{i t}}{\partial F}$. Since $p_{i j t} \frac{\partial Q_{i j t}}{\partial F}=$ $\left(\frac{\sigma}{\sigma-1}\right) M R P F_{i j t}$, where $M R P F_{i j t}=\frac{\partial P_{i j t} Q_{i j t}}{\partial F}$ is the marginal revenue product of factor $F$, these reallocation gains will only be present if there are gaps in marginal revenue products.
} 


$$
\pi_{i j t}=P_{i j t} Q_{i j t}-w_{s t}\left(1+\tau_{L i t}\right) L_{i j t}-R_{s t}\left(1+\tau_{K i t}\right) K_{i j t}-c_{t} M_{i j t},
$$

where $P_{i j t}$ is the firm's output price, $w_{s t}$ is the wage, $R_{s t}$ is the user cost of capital, $c_{t}$ is the price of materials. The potential firm-level capital and labor distortions are measured by $\tau_{K i t}$ and $\tau_{\text {Lit }}$, respectively. The first-order conditions for capital and labor choices are given by:

$$
\begin{gathered}
M R P K_{i t}=\alpha\left(\frac{\sigma-1}{\sigma}\right)\left(\frac{P_{i t} Q_{i t}}{K_{i t}}\right)=R_{s t}\left(1+\tau_{K i t}\right), \\
M R P L_{i t}=\beta\left(\frac{\sigma-1}{\sigma}\right)\left(\frac{P_{i t} Q_{i t}}{L_{i t}}\right)=w_{s t}\left(1+\tau_{L i t}\right),
\end{gathered}
$$

where $M R P K_{i j}$ and $M R P L_{i j}$ are the marginal revenue products of capital and labor, respectively. Some of these distortions, $\tau$, are nonfinancial and capture frictions such as firing costs and discounts in the sale of capital. We assume that financial frictions also potentially affect these distortions and model increases in the credit supply faced by a firm as a reduction in these distortions. ${ }^{29}$ The idea that greater availability of bank credit translates into reduced financial distortions is likely to be true for young firms.

We simplify our analysis by assuming that $\left(A_{i t}, M R P K_{K i t}, M R P L_{L i t}\right)$ are jointly log-normally distributed in an industry-year. Our analysis focuses on the intensive-margin allocation of resources and examines how changes in the composition of bank credit shape industry productivity conditional on a distribution of existing firms. Given this intensive-margin focus, the number of firms $N_{j t}$ and the joint distribution of their characteristics $\left(A_{i t}, 1+\tau_{K i t}, 1+\tau_{L i t}, s(i, t), g(i, t)\right)$ in the industry are exogenous to the firms.

\footnotetext{
${ }^{29}$ In principle, the availability of credit at the firm level could also affect the nonfinancial distortions faced by firms. This drop in overall distortions will capture the net effect of reduced financial distortions on capital overall distortions.
} 
In this setting, the contribution of the allocation of resources to industry productivity can be summarized by measures of the dispersion of $\log \left(M R P L_{i t}\right)$ and $\log \left(M R P K_{i t}\right)$ within the industry. Motivated by our empirical analysis, we examine the implications of the potential misallocation of resources across firms with different productivity within the previous groups. Intuitively, the drop in aggregate industry productivity induced by this within-group misallocation will be captured by the dispersion of $\log \left(M R P L_{i t}\right)$ and $\log \left(M R P K_{i t}\right)$ within a group. Gaps in marginal revenue products within a group capture differences in distortions since all firms in a group face the same factor prices. Using a simple linear projection, we decompose firms' distortions within group $g$ as $\log \left(1+\tau_{F i t}\right)=b_{F}^{g}+a_{F}^{g} \times \log \left(A_{i t}\right)+\varepsilon_{F i t}^{g}$, where $\operatorname{Cov}\left(\varepsilon_{F i t}^{g}, \log \left(A_{i t}\right) \mid g, t\right)=0$. The parameter $a_{F}^{g}$ measures the incremental marginal product or distortion (in logs) predicted by a given increase in firm productivity within the group.

In the absence of this link between distortions and firm productivity, there are no (industry productivity) gains from reallocating resources across firms of different productivity within a group. The existence of this link is important in misallocation models and consistent with previous empirical evidence (Bartelsman et al. (2013)). Building on this research, we assume that $a_{K}^{g}$ and $a_{L}^{g}$ are positive and find direct support for this assumption in our data.

We define local misallocation losses $\left(L M L_{g t}\right)$ as the increase in industry productivity that would take place if distortions $\log \left(1+\tau_{K i t}\right)$ and $\log \left(1+\tau_{L i t}\right)$ became uncorrelated with firm productivity within a group, i.e. $a_{K}^{g}$ and $a_{L}^{g}$ became equal to zero. We abstract away from potential changes in the misallocation of resources across groups and hold the mean value of these distortions in each group constant in this exercise. Appendix B shows that we can write these local misallocation losses $\left(L M L_{j g t}\right)$ as: 


$$
L M L_{j g t}=\frac{\beta_{j}}{2}\left[1+\beta_{j}(\sigma-1)\right] \sigma_{L g t}^{2}+\frac{\alpha_{j}}{2}\left[1+\alpha_{j}(\sigma-1)\right] \sigma_{K g t}^{2}+\alpha_{j} \beta_{j}(\sigma-1) \sigma_{K L g t},
$$

where $\sigma_{F g t}^{2}=\operatorname{Share~}_{g}\left(a_{F}^{g}\right)^{2} \sigma_{A g t}^{2}$ and $\sigma_{K L g t}^{2}=$ Share $_{g} a_{K}^{g} a_{L}^{g} \sigma_{A g t}^{2}$ capture the drop in $\sigma_{F t}^{2}=$ $\operatorname{Var}_{t}\left[\log \left(M R P F_{i t}\right)\right]$ and $\sigma_{K L t}=\operatorname{Cov}_{t}\left[\log \left(M R P K_{i t}\right), \log \left(M R P L_{i t}\right)\right]$, respectively, that would take place if the previous within-group link between productivity and distortions was eliminated. Share $_{g}$ is the share of firms in the industry-year in group $g$ and $\sigma_{A g t}^{2}=\operatorname{Var}\left(\log \left(A_{i t}\right) \mid g, t\right){ }^{30}$

We examine how a more positive link between credit supply and firm productivity (credit composition effect) affects the previous misallocation losses. We hold the distribution of firm productivity constant in this exercise. As in models of finance and misallocation, we assume that financial frictions affect the cost using capital, which needs to be financed upfront. This effect of the composition of credit on capital is captured by a drop in $a_{K}^{g}$.

In contrast with previous models of finance and misallocation, but consistent with recent empirical research on finance and labor, we argue that financing frictions can also affect firms' marginal cost of using labor. This labor financing effect could be significant for multiple reasons. One reason is that financial distress might affect the cost of using labor. As firms have greater access to credit, these financial distress costs associated with labor can be reduced. For example, the existence of firing and training costs might limit firms' ability to adjust their labor downwards after a negative shock, and labor can create operating leverage (wages are rigid). As firms expand their labor, operating leverage becomes more significant and the costs of financial distress

\footnotetext{
${ }^{30}$ Note that the TFP measure used in the previous empirical analysis captures revenue productivity and is different from firm real productivity $\left(A_{i t}\right)$. In order to relate to the empirical analysis, we can also define firm productivity here as the equivalent of TFP in the context of the model. In our framework, these two measures are related within a group. All results and conclusions here discussed remain unchanged if we use TFP as our measure of productivity.
} 
increase. ${ }^{31}$ Alternatively, financial distress might expose workers to significant costs and firms might need to compensate workers upfront for taking such risks, increasing firms' cost of using labor (Titman (1984), Berk, Stanton, and Zechner (2010)). ${ }^{32}$

Similarly, if firing or losing workers during financial distress is costly for firms, the risk of such distress can increase firms' upfront cost of using labor. Another reason for a labor financing effect is the potential need to finance labor expansions. Firms will need financing to employ more labor if there is a timing delay between payments to workers and the cash flows generated by the use of labor - a net working capital channel that has been recently emphasized theoretically by Jermann and Quadrini (2012) and empirically by Paravisini et al. (2014). Firms also often face training and hiring costs, and firm-specific investments by workers can be important, so expanding labor often requires upfront costs that need to be financed. These different economic mechanisms share a common prediction that financial distortions can affect firms’ marginal cost of using labor. We model labor distortions in an analogous way to capital distortions and allow the composition of credit to also reduce $a_{L}^{g}$.

${ }^{31}$ Consistent with this idea, Serfling (2016) provides evidence suggesting that firing costs in the U.S. can significantly increase the costs of financial distress through increases in operating leverage. Using cross-country data, Simintzi, Vig, and Volpin (2015) provide evidence supporting the view that employment protection legislations lead to an increase in the cost of financial distress through this same operating leverage channel.

${ }^{32}$ Graham et al. (2016) directly estimate that the labor-market cost of bankruptcy for employees is important and provide evidence that these costs significantly increase the upfront wages paid by firms. Agrawal and Matsa (2013) provide evidence also consistent with the idea that the ex-post costs of financial distress for employees increase the upfront costs for firms of using labor. 
We assume that this credit composition effect happens simultaneously for all groups (young and old) in a region with potentially different magnitudes across the groups. We allow the price of industry output and factor prices to change together with these credit effects. This incorporates potential shifts in demand and input markets faced by firms after the credit effects. In this framework, the previous shift in the allocation of credit always reduces local misallocation losses. This shift leads firm productivity to become less positively correlated with distortions and reduces the dispersion of marginal products drops within the group. Moreover, the number of regions affected by the credit composition effects and changes in industry output or input prices do not affect this analysis. Conditional on basic parameters, changes in the correlation between distortions and firm productivity are sufficient to determine the previous drop in the dispersion of marginal products. Additionally, one can evaluate the importance of this effect by examining changes in the marginal revenue product gap predicted by differences in firm productivity within a group.

This framework also allows one to formally analyze whether labor might be a "sideshow". Labor is defined to be a sideshow if increases in credit supply reduce firms' capital distortions but do not change their labor distortions. In this case, the local composition of credit will only affect industry productivity by changing the distribution of $M R P K$ (capital misallocation effect) and changes in the distribution of $M R P L$ will play no role in explaining changes in local misallocation (labor misallocation effect). Note that, even if credit does not affect firms' cost of using labor, the previous credit composition effects will still be matched with labor reallocation towards more productive firms. This comes from the fact that capital and labor are complements and a relative capital expansion by more productive firms also leads to a relative labor expansion by these same firms. The gaps in MRPL within a region will not change in this case because labor will be reallocated across firms to keep these gaps constant. In contrast, labor misallocation effects can be 
important if the composition of credit affects labor distortions. The key pattern that allows one to disentangle these two cases is the $M R P L$ gap between more and less productive firms. This gap will only be reduced in the case where labor is not a sideshow.

\section{B. Do We Observe a Convergence in Marginal Product Gaps?}

We examine if our previous results on the effects of state banking deregulation are matched with a convergence of the marginal revenue products of local firms with different productivity. This is the central qualitative prediction of the previous framework. One challenge in the implementation of this analysis is that banking deregulation might affect the dispersion of marginal products through additional mechanisms other than changes in the composition of credit supply. As in the previous empirical analysis, we address this issue by contrasting the relative effects for more productive firms among young and old firms. We estimate specifications from our financial policy results (Table VI) using simple measures of gaps in firms' marginal revenue products as the outcome variables. As in our financial results, this analysis focuses on longer-term changes in outcomes across census years given that gaps in marginal revenue products can only be measured for broad samples of small firms during these years. We focus on the specifications including an interaction with Young. We therefore rely on this age interaction to control for demand effects. ${ }^{33}$

We measure gaps in firms' marginal revenue products of labor using $\log (M R P L)=$ $\log \left(\frac{R e v}{L}\right)$, where Rev is firms' revenue. Note that variation in this variable within an industrystate-age group-year will capture gaps in firms' marginal revenue product of labor (in logs) if firms' labor elasticity is constant within these groups. This will be the case if firms have CobbDouglas revenue functions with parameters that depend only on these groups, a specification that

\footnotetext{
${ }^{33}$ Recall that the previous results suggest that this interaction is not capturing changes in credit demand.
} 
is more flexible than the one in the previous model. ${ }^{34}$ We measure gaps in firms' marginal revenue products of capital in an analogous way. As in our previous results, we report scaled coefficients to capture differences between firms in the top and bottom quartiles of firm productivity.

Table IX reports the results. Column (1) reports results using the specification in Panel B of Table VI. Banking deregulation is associated with a significant reduction in the relative labor marginal product of high productivity firms in the group of young firms. This effect is economically significant and implies that deregulation (change in Dereg between 0 and 2) is associated with a 5\% drop in the relative marginal product of these firms. This drop represents a convergence of marginal products because, prior to deregulation, there is a significant positive link within an industry-state-year between the marginal product of labor and the productivity of young firms in our sample. This estimated convergence effect represents a drop of $12 \%$ in the magnitude of this initial link. The results show that this convergence in the marginal product of labor is robust across different specifications. Column (2) considers the interaction of the specification in Panel C of Table VI with age. All independent variables in this last specification are interacted with Young. The coefficient of interest Dereg $\times$ TFP $\times$ Young estimates the differential value of the coefficient Dereg $\times$ TFP among young firms. We use a sample that is significantly larger than the one used in Table VI and are able to include interactions of both state fixed effects and year fixed effects with TFP as controls. Therefore, the identification of the effect of interest is similar to the

\footnotetext{
${ }^{34}$ In general, we can write the marginal revenue product of labor for firm $i$ in year $\operatorname{tas} \log \left(M R P L_{i t}\right)=\log \left(\frac{\operatorname{Rev} i t}{L_{i t}}\right)+$ $\log \left(\beta_{i t}\right)$, where $\beta_{i t}$ is the labor elasticity. If $\log \left(\beta_{i t}\right)$ is constant within an industry-state -age group-year, it will be absorbed by the fixed effects in the specification analyzed here.
} 
one in Column (1) and is based only on the differential changes for young firms in the link between MRPL and TFP around deregulation events. When compared to the previous result, the estimated effect following this approach becomes economically stronger.

(Insert Table IX here)

Columns (3) to (5) show that these results remain important when we focus on a broader group of young firms with age between 1 and 10 years. In the analysis that follows, we focus on these estimates based on a broader group of affected firms while quantifying the implications of the results for aggregate industry productivity. Finally, Column (6) shows that these estimates are matched with an economically similar effect for capital. As in the context of labor, we confirm that this effect captures a convergence in the relative marginal products of firms with different productivity. Overall, this analysis suggests that the previous results lead to industry productivity gains and that labor misallocation effects plays a significant role in driving such gains.

\section{Quantification of Implied Industry Productivity Gains}

We analyze the magnitude of the industry productivity gains implied by our last results. The quantification of these implications requires additional assumptions about specific parameters and functional forms in the model. We interpret this analysis as simply describing what a standard model of misallocation used in the literature, and reasonable parameter values, would imply for the magnitudes of our results. We describe here our main findings and provide greater detail in Appendix C. We assume that the credit composition effect analyzed in Section IV.B takes place for all states simultaneously and consider the gains for industry aggregate output. This gain is the sum of the drops in local misallocation losses across regions. We evaluate this gain using Equation (8) together with the previous expressions for $\sigma_{L g t}^{2}, \sigma_{K g t}^{2}$, and $\sigma_{K L g t}$. We use the values for $\beta_{j}, \alpha_{j}$, and $\sigma_{A g t}^{2}$ implied by our estimates for firm productivity and follow the literature in setting values 
for $\sigma$ between three and four. We use the estimates for changes in $a_{L}^{g}$ and $a_{K}^{g}$ from Table IX (Column (3) and (6)), which capture our broadest group of affected firms. We estimate the initial link between firms' marginal revenue products and TFP prior to deregulation and use these estimates as initial values for $a_{L}^{g}$ and $a_{K}^{g}$. This allows one to consider values for these parameters before and after deregulation. This is the only source of change in our analysis and is intended to capture the previous shift in the composition of credit. Additionally, we also need to measure the share of firms in the groups. Since we are adding effects across all regions we here use the average share of young single-plant firms across industries. In the context of this analysis, we define young firms as firms with 10 years or less and 56\% of firms in our data are young single-plant firms.

Table $\mathrm{X}$ reports the magnitudes from this analysis. We report output gains in terms of value added because it avoids double counting output across industries. ${ }^{35}$ The results imply gains in aggregate industry value added between $1.1 \%$ and $2.1 \%$. These magnitudes are not sensitive to the choice of $\sigma$ and are between $2.0 \%$ and $2.1 \%$ once one focuses on industries in the top tercile of productivity dispersion. These effects capture gains over a period of approximately five years. We also report implied drops in previous local misallocation losses of $24 \%$. Additionally, we also consider the percentage increase in the gross output of young single-plant firms necessary to generate the same increases in industry value added. One can interpret these increases as the

\footnotetext{
${ }^{35}$ We model gross output production functions because this approach requires weaker assumptions (Petrin and Levinsohn (2012)) but we analyze how gross output gains translate into value added gains. In our framework, we can write industry value added as $V A_{j t}=P_{j t} Q_{j t}-c_{t} M_{j t}$. Conditional on $P_{j t}$, $c_{t}$, and $M_{j t}$, incremental gains in industry gross output $\left(\Delta \ln \left(Q_{j t}\right)\right)$ lead to value added gains given by $\Delta \ln \left(V A_{j t}\right) \approx$ $\left(\frac{P_{j t} Q_{j t}}{V A_{j t}}\right) \Delta \ln \left(Q_{j t}\right)$. Therefore, we can use the ratio of industry sales to value added to convert these gains.
} 
equivalent gains in the (revenue) firm-level productivity of these firms necessary to replicate the previous effects. We estimate that these equivalent increases are economically large and represent implied increases in firm productivity between 3.3\% and 6.2\%.

(Insert Table $\mathrm{X}$ here)

Finally, we consider the role of labor in quantitatively driving these implied gains. We follow a simple approach to decompose the previous estimates into capital and labor misallocation effects. We first compute the gains assuming that only $a_{K}^{g}$ drops and there is no labor misallocation effect. We then estimate the incremental gains associated with the drop in $a_{L}^{g}$ at the new lower value for $a_{K}^{g}$. This gives us a contribution of reductions in labor misallocation. We compute the percentage of the total gains associated with each of these components. We find that $85 \%-86 \%$ of the gains come from the drop in labor misallocation. Since the estimated drops in $a_{K}^{g}$ and $a_{L}^{g}$ is similar, this gap comes from the difference in factor shares. Our analysis suggests that the previous credit effects lead to comparable changes in the costs of using capital and labor but that the labor effect is quantitatively more important because the labor share in production is significantly larger.

\section{Conclusions}

We study how state banking deregulation in the U.S. shapes the allocation of resources across firms with different productivity within local nonfinancial industries. We find that the deregulation of local U.S. banking markets leads to significant increases in the relative employment and capital growth of young, high productivity firms. We use financial data for a broad range of firms to provide evidence that a shift in the composition of bank credit supply towards these same young, high-productivity firms accompanies these real resource reallocations. We provide evidence that alternative mechanisms, such as changes to local demand and other local economic conditions, do not explain our growth results. 
Intuitively, this reallocation effect due to bank lending should translate into gains in aggregate industry productivity. We build on a standard monopolistic competition framework used in the misallocation literature to explicitly consider the implications of this effect for aggregate industry productivity. We then use this framework to quantify the implications of our results for aggregate industry productivity. We find that our results imply significant gains in aggregate industry productivity. In contrast with typical models connecting finance to aggregate productivity, we find that the reallocation of labor plays an important role in explaining these gains. We highlight how this role of labor should be important if the availability of credit affects firms' cost of using labor.

Overall, our analysis suggests that increased competition in local banking markets increases credit to young, highly productive firms and can impact aggregate industry productivity. More broadly, our emphasis on the composition of bank lending and the allocation of labor complements previous evidence on the real effects of other reforms to financial or banking markets. Our results suggest the importance of incorporating bank competition and the allocation of labor when modeling the potential implications of finance for industry productivity. 


\section{REFERENCES}

Adelino, Manuel, Song Ma, and David T. Robinson. "Firm age, investment opportunities, and job creation." (2016), The Journal of Finance, forthcoming

Agrawal, Ashwini K., and David A. Matsa. "Labor unemployment risk and corporate financing decisions." Journal of Financial Economics 108.2 (2013): 449-470.

Amel, Dean. "State laws affecting the geographic expansion of commercial banks." Board of Governors, unpublished paper, (1993).

Autor, David H., and Mark G. Duggan. "The rise in the disability rolls and the decline in unemployment." The Quarterly Journal of Economics 118.1 (2003): 157-206.

Bartelsman, Eric, John Haltiwanger, and Stefano Scarpetta. "Cross-country differences in productivity: The role of allocation and selection." The American Economic Review 103.1 (2013): 305-334.

Bartik, Timothy J. "Boon or boondoggle? The debate over state and local economic development policies." (1991). Upjohn Press.

Beck, Thorsten, Ross Levine, and N. Loayza. "Finance and the sources of growth." Journal of Financial Economics 58.1 (2000): 261-300.

Becker, Bo, and Victoria Ivashina. "Cyclicality of credit supply: firm level evidence." Journal of Monetary Economics 62 (2014): 76-93.

Benmelech, Efraim, and Nittai K. Bergman. "Bankruptcy and the collateral channel." The Journal of Finance 66.2 (2011): 337-378. 
Berk, Jonathan B., Richard Stanton, and Josef Zechner. "Human capital, bankruptcy, and capital structure." The Journal of Finance 65.3 (2010): 891-926.

Bertrand, Marianne, Antoinette Schoar, and David Thesmar. "Banking deregulation and industry structure: evidence from the French banking reforms of 1985." The Journal of Finance 62.2 (2007): 597-628.

Blanchard, Olivier Jean, and Lawrence F. Katz. "Regional evolutions." Brookings Papers on Economic Activity 23.1 (1992): 1-76.

Chodorow-Reich, Gabriel. "The employment effects of credit market disruptions: firm-level evidence from the 2008-9 financial crisis." The Quarterly Journal of Economics 129.1 (2014): 1-59.

Ellison, Glenn, Edward L. Glaeser, and William R. Kerr. "What causes industry agglomeration? Evidence from coagglomeration patterns." The American Economic Review 100.3 (2010): 1195-1213.

Giroud, Xavier, and Holger M. Mueller. "Capital and labor reallocation within firms." The Journal of Finance 70.4 (2015): 1767-1804.

Graham, John, Hyunseob Kim, Si Li, and Jiaping Qiu, "Employee Costs of Corporate Bankruptcy,” working paper Duke University, 2016.

Guiso, Luigi, Paola Sapienza, and Luigi Zingales. "The role of social capital in financial development." The American Economic Review 94.3 (2004): 526-556.

Haltiwanger, John, Ron S. Jarmin, and Javier Miranda. "Who creates jobs? Small versus large versus young." Review of Economics and Statistics 95.2 (2013): 347-361.

Holmstrom, Bengt, and Jean Tirole. "Financial intermediation, loanable funds, and the real sector." the Quarterly Journal of economics 112.3 (1997): 663-691. 
Hsieh, Chang-Tai, and Peter J. Klenow. "Misallocation and manufacturing TFP in China and India." The Quarterly Journal of Economics 124.4 (2009): 1403-1448.

Hsieh, Chang-Tai, and Peter J. Klenow. "The life cycle of plants in India and Mexico." The Quarterly Journal of Economics 129.3 (2014): 1035-1084.

Huang, Rocco R. "Evaluating the real effect of bank branching deregulation: Comparing contiguous counties across US state borders." Journal of Financial Economics 87.3 (2008): 678-705.

Jayaratne, Jith, and Philip E. Strahan. "The finance-growth nexus: evidence from bank branch deregulation." The Quarterly Journal of Economics 111.3 (1996): 639-670.

Jayaratne, Jith, and Philip E. Strahan. "Entry restrictions, industry evolution, and dynamic efficiency: evidence from commercial banking." The Journal of Law and Economics 41.1 (1998): 239-274.

Jermann, Urban, and Vincenzo Quadrini. "Macroeconomic effects of financial shocks." The American Economic Review 102.1 (2012): 238-271.

Kashyap, Anil K., Jeremy C. Stein, and David W. Wilcox. "Monetary policy and credit conditions: evidence from the composition of external finance." The American Economic Review 83.1 (1993): 78.

Kerr, William R., and Ramana Nanda. "Democratizing entry: banking deregulations, financing constraints, and entrepreneurship." Journal of Financial Economics 94.1 (2009): 124-149.

Krishnan, Karthik, Debarshi Nandy, and Manju Puri. "Does financing spur small business productivity? evidence from a natural experiment." Review of Financial Studies 28.6 (2015): 1768-1809. 
Kroszner, Randall S., and Philip E. Strahan. "What drives deregulation? economics and politics of the relaxation of bank branching restrictions." The Quarterly Journal of Economics 114.4 (1999): 1437-1467.

Larrain, Mauricio, and Sebastian Stumpner. "Capital account liberalization and aggregate productivity: the role of firm capital allocation." (2016). The Journal of Finance, forthcoming

Lee, Dong, Han Shin, and René M. Stulz. "Why does capital no longer flow more to the industries with the best growth opportunities?" No. w22924. National Bureau of Economic Research, 2016.

Maksimovic, Vojislav, Gordon Phillips, and Liu Yang. "Private and public merger waves." The Journal of Finance 68.5 (2013): 2177-2217.

Mian, Atif, Amir Sufi, and Emil Verner. "How do credit supply shocks affect the real economy? Evidence from the United States in the 1980s." Working paper (2017).

Moll, Benjamin. "Productivity losses from financial frictions: can self-financing undo capital misallocation?" The American Economic Review 104.10 (2014): 3186-3221.

Olley, G. Steven, and Ariel Pakes. "The dynamics of productivity in the telecommunications equipment Industry." Econometrica 64.6 (1996): 1263-1297.

Pagano, Marco, and Giovanni Pica. "Finance and employment." Economic Policy 27.69 (2012): 5-55.

Paravisini, Daniel, et al. "Dissecting the effect of credit supply on trade: evidence from matched credit-export data." The Review of Economic Studies 82.1 (2015): 333-359.

Petersen, Mitchell A., and Raghuram G. Rajan. "The benefits of lending relationships: evidence from small business data." The Journal of Finance 49.1 (1994): 3-37. 
Petersen, Mitchell A., and Raghuram G. Rajan. "The effect of credit market competition on lending relationships." The Quarterly Journal of Economics 110.2 (1995): 407-443.

Petersen, Mitchell A., and Raghuram G. Rajan. "Does distance still matter? The information revolution in small business lending." The Journal of Finance 57.6 (2002): 2533-2570.

Petrin, Amil, and James Levinsohn. "Measuring aggregate productivity growth using plant-level data." The RAND Journal of Economics 43.4 (2012): 705-725.

Serfling, Matthew. "Firing costs and capital structure decisions." The Journal of Finance 71.5 (2016): 2239-2286.

Simintzi, Elena, Vikrant Vig, and Paolo Volpin. "Labor protection and leverage." Review of Financial studies 28.2 (2014): 561-591.

Titman, Sheridan. "The effect of capital structure on a firm's liquidation decision." Journal of Financial Economics 13.1 (1984): 137-151.

Wurgler, Jeffrey. "Financial markets and the allocation of capital." Journal of Financial Economics 58.1 (2000): 187-214.

Zarutskie, Rebecca. "Evidence on the effects of bank competition on firm borrowing and investment." Journal of Financial Economics 81.3 (2006): 503-537. 


\section{Appendix A - Variable Definitions}

As described in Section II, our main data sources are the Longitudinal Business Database (LBD), the Census of Manufacturers (CM), and the Quarterly Financial Reports (QFR) from the U.S. Census Bureau. Across all variables, industries are defined as 3-digit SIC codes.

Employment - total firm employment from the LBD. Given our sample of single-plant firms, this is the same as total establishment employment.

Employment Growth - change in the log of firm employment between years $t$ and $t-1$.

Dereg - banking deregulation index that equals the sum of Intrastate_Dereg and Interstate_Dereg, which are indicators that equal one if the state has passed intrastate and interstate banking deregulation, respectively.

Sales - total value of shipments from the CM adjusted with industry deflator. This value is based on the last CM.

Young1, Young2, Old - Young1 is the group of firms present for the first time in the last CM. Young2 is the group of firms present for the first time in the CM prior to the last one. Old includes all firms present in a prior $\mathrm{CM}$ which are not included in the two previous groups.

Age1 and Age2 - Age1 is the firm's age measured using the LBD, i.e. number of years since first appearance in the LBD. Age2 is the squared value of Age1.

Large - indicator variable that equals one if the firm is above the median employment in a given year and age group (Young1, Young2, and other firms).

TFP - log of firm total factor productivity. We specify Cobb-Douglas production functions at the plant-level with parameters that depend on an industry-year. Firm productivity is the same as plant productivity in our sample of single-plant firms. The output in the production function is industrydeflated sales. The inputs are the capital stock, labor (total hours), and total material costs. Production function parameters for an industry-year are estimated using plant-level data from the Annual Survey of Manufacturers (ASM) for the last five years. The ASM provides annual plant-level data for a random subsample of plants. TFP is measured in the latest CM using values for the output and inputs in that CM combined with the estimated production function parameters for that industry-year. In the Internet Appendix we consider alternative measures of firm TFP using different approaches to estimate the production function parameters.

Capital Stock Growth - change in the firms' capital stock between the end of years $t$ and $t-1$, from the CM.

Young (Age 1-10), Young (Age 1-5), Young (Age 6-10), and Old (11+) - age groups constructed during Census years based on the number of years since the first appearance of the firm in the CM. 
Bank Debt Share - ratio of bank debt (from commercial banks) to the sum of bank debt and non-bank debt from the QFR (balance sheet information).

Bank Debt Ratio - ratio of bank debt (from commercial banks) to the book value of total assets from the QFR (balance sheet information).

Non-Bank Debt Ratio - ratio of non-bank debt (from other sources, excluding commercial banks) to the book value of total assets from the QFR (balance sheet information).

IDereg - value of Dereg at the start of the sample (1977).

Pre - indicator that equals one prior to the deregulation wave (in years 1977 and 1982). This variable is used in specifications estimated only with Census years.

Shock (Table VII) - In Panel A, Shock is a predicted shock to state economic conditions between 1977 and 1993 (sample period). For each state, we first determine the initial share (in 1977) of the total employment in each industry (initial share). We then estimate the national-level employment growth of each industry in this list using only data for other states (national industry growth). The predicted growth is the weighted average of these national growth rates across industries, where the previous initial shares are used as weights. In Panel B, Shock is the state's aggregate employment growth between 1977 and 1993 (sample period). All these employment variables are based on LBD employment data.

Shock (Table VIII) - In Panel A, Shock is a predicted shock to state economic conditions between 1977 (first sample year) and the current year, constructed in an analogous way to Panel A of Table VII. Initial shares are based on 1977 and the national-level growth rate of each industry is defined between 1977 and the current year. In Panel B, Shock is the state's aggregate employment growth between 1977 and the current year. . In Panels C to E, Shock is predicted in analogous way to Panel A, but only includes a subset of local industries for each industry-state. More specifically, for each given industry, we first define connected industries at the national level (see below). When predicting a shock for a given industry-state we only include connected industries in the same state. The predicted growth for connected industries is the weighted average of the national growth rates across industries, defined in the same way as in Panel A, but now restricted to this subset of connected industries. This predicted growth is multiplied by the initial share of connected industries in the state to better capture the magnitude of the shock. We follow Ellison, Glaeser, and Kerr (2010) in the definition of connections. In Panels $C$ and D, connected industries are defined using the Benchmark Input-Output Accounts published by the Bureau of Economic Analysis (BEA). Panel C classifies industry $j$ as connected (buyer) to industry $i$ if it purchases at least $5 \%$ of the total sales from industry $i$. Panel D classifies industry $j$ as connected (seller) to industry $i$ if at least $5 \%$ of the total inputs used by industry $i$ comes from industry $j$. In Panel E, connected industries are defined using the National Industrial-Occupation Employment Matrix (NIOEM) published by the Bureau of Labor Statistics (BLS). The NIOEM provides industry-level employment in 277 occupations, and we first estimate the share of each industry across occupations. We then measure the similarity of the labor used by two industries by measuring the correlation of their shares across different occupations. Industries are classified as connected if their correlation is in the top $25 \%$ of the distribution across all industry pairs. 
MRPL and MRPK (Table IX) - MPRPL is the log of the ratio of sales to labor (total hours). MPRPK is the log of the ratio of sales to capital (capital stock). These variables are based on the CM and only defined in Census years.

\section{Appendix B - Analysis of Model of Misallocation and Industry Productivity}

We show how the model in Section VI.A leads to the expression for local misallocation losses $\left(L M L_{j g t}\right)$ in the text (Equation (8)). We also provide more economic intuition on the logic behind this result.

We start by describing in detail the intuition for a key point in this framework: gaps in firms' marginal revenue products translate into lower aggregate industry productivity (misallocation losses).

Intuitively, industry productivity can be increased by reallocating factor $F$ from firm $i$ to firm $k$ only if $p_{k t} \frac{\partial Q_{k t}}{\partial F}>p_{i t} \frac{\partial Q_{i t}}{\partial F}$. In other words, we can evaluate the contribution of products to industry productivity using their prices. This follows from the fact that the marginal rate of transformation (MRT) for two products in the industry production function (representative firm) is given by their relative price, i.e., $M R T_{j t}^{i, i^{\prime}}=\frac{P_{i j t}}{P_{i^{\prime} j t}}$.

This intuitive result comes directly from the first-order condition for the problem of the representative firm: $\max _{Q_{i j t}}\left\{P_{j t} Q_{j t}-\sum_{i} P_{i j t} Q_{i j t}\right\}$, where $Q_{j t}=\left(\sum_{i} Q_{i j t}^{\frac{\sigma-1}{\sigma}}\right)^{\frac{\sigma}{\sigma-1}}$ and the representative firm is buying output from firms in the industry. This problem leads to a demand for differentiated products with a constant price elasticity $\sigma$ and given by: $\left(\frac{Q_{i j t}}{Q_{j t}}\right)=\left(\frac{P_{i j t}}{P_{j t}}\right)^{-\sigma}$. The revenue function of the firm is given by $R_{i j t}=P_{i j t} Q_{i j t}$ and from this the marginal revenue products of any given factor can be written as $\frac{\partial R_{i j t}}{\partial F_{i j t}}=P_{i j t} \frac{\partial Q_{i j t}}{\partial F_{i j t}}+\frac{\partial P_{i j t}}{\partial F_{i j t}} Q_{i j t}$. Given a constant elasticity of demand, this leads to $\mathrm{MRPF}_{\mathrm{ijt}} \equiv \frac{\partial R_{i j t}}{\partial F_{i j t}}=$ $P_{i j t} \frac{\partial Q_{i j t}}{\partial F_{i j t}}\left(\frac{\sigma-1}{\sigma}\right)$.

Therefore, in this framework, resource reallocation across different firms can translate into industry productivity gains if the marginal revenue products of these firms are not equalized. Conditional on a distribution of firm TFP, industry productivity will be maximized at the point where marginal revenue products are equalized across firms. 
As a first step in the analysis of local misallocation losses, we derive a general expression for industry TFP. Recall that we simplify our analysis by assuming that characteristics $\left(A_{i t}, M R P K_{i t}, M R P L_{i t}\right)$ are jointly log-normally distributed in an industry-year. Before imposing this last condition, we can obtain a general expression for industry TFP as:

$\left.T F P_{j t}=\frac{\left\{\sum_{i}\left(\frac{A_{i j t}}{\left(M R P K_{i t}\right)^{\alpha_{j}}\left(M R P L_{i t}\right)^{\beta_{j}}}\right)^{\sigma-1}\right\}^{\frac{\sigma}{\sigma-1}-\gamma_{j}}}{\left(\sum_{i} \frac{\left(A_{i t}{ }^{\sigma-1}\right)\left(M R P L_{i t}\right)^{-1}}{\left.\alpha^{\alpha}\right)^{(\sigma-1)}\left(M R P L_{i t}\right)^{\beta_{j}(\sigma-1)}}\right)^{\beta_{j}}\left(\sum_{i} \frac{\left(A_{i t}{ }^{\sigma-1}\right)\left(M R P K_{i t}\right)_{j}\left({ }^{\alpha}\right)^{-1}}{(M-1)}\left(M R L_{i t}\right)^{\beta_{j}(\sigma-1)}\right.}\right)^{\alpha_{j}}$.

This general expression for industry TFP is derived by first writing TFP using marginal products of labor (L), capital (K) and materials (M) as follows:

$$
T F P_{j t}=\left\{\sum_{i}\left[A_{i j t}\left(\frac{\overline{M R P L_{j t}}}{M R P L_{i j t}}\right)^{\beta_{j}}\left(\frac{\overline{M R P K_{j t}}}{M R P K_{i j t}}\right)^{\alpha_{j}}\left(\frac{\overline{M R P M_{j t}}}{M R P M_{i j t}}\right)^{\gamma_{j}}\right]^{\sigma-1}\right\}^{\frac{1}{\sigma-1}}
$$

where $\overline{M R P F_{j t}} \triangleq \beta_{j}\left(\frac{\sigma-1}{\sigma}\right)\left(\frac{P_{j t} Q_{j t}}{F_{j t}}\right)=\frac{1}{\sum_{i}\left(\frac{1}{M P R F_{i j t}}\right)\left(\frac{P_{i j t} Q_{i j t}}{P_{j t} Q_{j t}}\right)}$ is a weighted average of firms' marginal revenue products in the industry for factors $\mathrm{F}=\mathrm{L}, \mathrm{K}$ and $\mathrm{M}$ respectively. The representative firm's production function and the demand function for differentiated products together imply that $\sum_{i} \frac{P_{i j t} Q_{i j t}}{P_{j t} Q_{j t}}=1$.

In order to derive Equation (B.1) from the previous expression for industry TFP, we need to combine it with the demand for differentiated products and a pricing equation. The demand equation implies that $\left(\frac{P_{i j t} Q_{i j t}}{P_{j t} Q_{j t}}\right)=\frac{P_{i j t}^{1-\sigma}}{\sum_{i} P_{i j t}^{\sigma}}$, which can be substituted into the previous formula for $\overline{M R P F_{j t}}$. The pricing equation is given by $P_{i j t}=\frac{\left(M R P K_{i t}\right)^{\alpha_{j}}\left(M R P L_{i t}\right)^{\beta_{j}}\left(M R P M_{i t}\right)^{\gamma_{j}}}{A_{i j t}}\left(\frac{\sigma}{\sigma-1}\right)\left(\frac{1}{\alpha_{j}{ }^{\alpha_{j}} \beta_{j}{ }^{\beta_{j}} \gamma_{j}{ }^{\gamma_{j}}}\right)$. Using the pricing equation after the last step leads to Equation (B.1). Firms face a constant elasticity of demand, which implies that $P_{i j t}=\left(\frac{\sigma}{\sigma-1}\right) \mathrm{C}_{\mathrm{ijt}}^{\prime}\left(\mathrm{Q}_{\mathrm{ijt}}\right)$, where $\mathrm{C}_{\mathrm{ijt}}\left(\mathrm{Q}_{\mathrm{ijt}}\right)$ is the cost minimization function. The pricing equation comes from combining this mark-up condition with a Cobb-Douglas cost function and the first order conditions for $M R P K_{i t}$ and $M R P L_{i t}$ in the text (Equation (7)).

Equation (B.1) allows us to write industry TFP as a general function of the distribution of firm productivity and marginal revenue products in the industry and is analogous to Equation (15) in Hsieh and Klenow (2009, hereafter HK). This expression can be significantly simplified if we assume that 
the characteristics $\left(A_{i t}, M R P K_{i t}, M R P L_{i t}\right)$ are jointly log-normally distributed in an industry-year - additional assumption in Section VI.A. In this case, we can write:

$\log \left(T F P_{j t}\right)=\log \left(T F P_{j t}^{*}\right)-\beta_{j}\left[1+\beta_{j}(\sigma-1)\right] \frac{\sigma_{L t}^{2}}{2}-\alpha_{j}\left[1+\alpha_{j}(\sigma-1)\right] \frac{\sigma_{K t}^{2}}{2}-\alpha_{j} \beta_{j}(\sigma-1) \sigma_{K L g t}$,

where $T F P_{j t}^{*}=\left(\sum_{i} A_{i j t}^{\sigma-1}\right)^{\frac{1}{\sigma-1}}$ is the TFP in the benchmark case where resources are allocated to equalize all marginal revenue products, $\sigma_{F t}^{2}=\operatorname{Var}_{t}\left[\log \left(M R P F_{i t}\right)\right]$ and $\sigma_{K L t}=$ $\operatorname{Cov}_{t}\left[\log \left(M R P K_{i t}\right), \log \left(M R P L_{i t}\right)\right]$. $\operatorname{Var}($.$) and \operatorname{Cov}($.$) here refer to industry moments.$

Equation (B.2) is analogous to a general version of Equation (16) in $\mathrm{HK}$ and can be derived from Equation (B.1) after applying statistical properties of a log-normal distribution. Specifically, Equation (B.1) has three main terms with sums across firms, which can be each written as $N_{j t} E\left(Z_{i j t}\right)$, where $E\left(Z_{i j t}\right)$ is the expected value in the industry of some log-normally distributed variable. Moreover, $Z_{i j t}$ is always a product of three log-normally distributed variables. If $\left(X_{1}, X_{2}, X_{3}\right)$ are joint lognormally distributed, we have $E\left(X_{1} X_{2} X_{3}\right)=E\left(X_{1}\right) \exp \left(\mu_{2}+\mu_{3}+\frac{\sigma_{2}{ }^{2}}{2}+\frac{\sigma_{3}{ }^{2}}{2}+\sigma_{23}+\sigma_{12}+\sigma_{13}\right)$, where $\mu_{i}$ and $\sigma_{i}$ is the mean and standard deviation of $\log \left(X_{i}\right)$, respectively, and $\sigma_{i j}$ is the covariance between $\log \left(X_{i}\right)$ and $\log \left(X_{j}\right)$. If we apply this property to the three previous expressions in Equation (B.1), we can obtain Equation (B.2) after some algebra.

We can use Equation (B.2) to derive the expression for local misallocation losses $\left(L M L_{j g t}\right)$ in the text in a simple way. Recall that these losses are defined as the increase in industry productivity that would take place if $a_{K}^{g}$ and $a_{L}^{g}$ became equal to zero. Also recall that $a_{K}^{g}$ and $a_{L}^{g}$ are defined as the incremental distortions (in logs) predicted within a group by a given increase in $\log \left(A_{i j t}\right)$. For each group $g$, we can write $\log \left(1+\tau_{F i t}\right)=b_{F}^{g}+a_{F}^{g} \times \log \left(A_{i j t}\right)+\epsilon_{F i t}^{g}$, where $\epsilon_{\text {Fit }}^{\mathrm{g}}$ is a residual from a linear projection of $\log \left(1+\tau_{\mathrm{Fit}}\right)$ on $\left(\log \left(A_{i j t}\right), 1\right)$ within the group. As explained in the text, we are assuming that the average value of $\log \left(1+\tau_{F i t}\right)$ in each group do not change in this exercise we abstract away from misallocation across groups. We are also holding the distribution of $\epsilon_{\text {Fit }}^{\mathrm{g}}$ constant - assumption that other distortions unrelated to productivity are not changing.

We can thus obtain equation 8 in the text as: 
$L M L_{j g t}=\frac{\beta_{j}}{2}\left[1+\beta_{j}(\sigma-1)\right] \sigma_{L g t}^{2}+\frac{\alpha_{j}}{2}\left[1+\alpha_{j}(\sigma-1)\right] \sigma_{K g t}^{2}+\alpha_{j} \beta_{j}(\sigma-1) \sigma_{K L g t}$,

where $\sigma_{F g t}^{2}$ and $\sigma_{K L g t}^{2}$ are the drops in $\sigma_{F t}^{2}=\operatorname{Var}_{t}\left[\log \left(M R P F_{i t}\right)\right]$ and $\sigma_{K L t}=$ $\operatorname{Cov}_{t}\left[\log \left(M R P K_{i t}\right), \log \left(M R P L_{i t}\right)\right]$, respectively, that would take place in this exercise. The drop in $\operatorname{Var}\left[\log \left(M R P F_{i t}\right) \mid g\right]=\operatorname{Var}\left[\log \left(1+\tau_{F i t}\right) \mid g\right]$ in this exercise is given by $\left(a_{F}^{g}\right)^{2} \sigma_{A g t}^{2}$, where $\sigma_{A g t}^{2}=\operatorname{Var}\left(\log \left(A_{i t}\right) \mid g\right)$. Note that $\mathrm{E}\left[\log \left(\mathrm{MRPL}_{\mathrm{i}}\right) \mid \mathrm{g}\right]$ does not change in this exercise. Combining these points, we have that $\sigma_{F g t}^{2}=$ Share $_{g}\left(a_{F}^{g}\right)^{2} \sigma_{A g t}^{2}$ and an analogous expression $\sigma_{K L g t}^{2}=$ Share $_{g} a_{K}^{g} a_{L}^{g} \sigma_{\text {Agt }}^{2}$, where Share $_{g}$ is the share of firms in the industry-year in group $g$. This is the expression in Equation (8).

The TFP measure used in the empirical analysis is revenue productivity and is based on an industrydeflated measure of output $Y_{i j t}=\frac{P_{i j t} Q_{i j t}}{D_{j t}}$, where $\mathrm{D}_{\mathrm{jt}}$ is an industry deflator. Using the demand for differentiated products, we can write $Y_{i j t}=\frac{P_{i j t} Q_{i j t}}{D_{j t}}=C_{j t}\left(Q_{i j t}\right)^{\left(\frac{\sigma-1}{\sigma}\right)}=C_{j t} A_{i j t}^{\left(\frac{\sigma-1}{\sigma}\right)} K_{i j t}^{\widetilde{\alpha}} L_{i j t}^{\widetilde{\beta}} M_{i j t}^{\widetilde{\gamma}}$ where $C_{j t}=\frac{B_{j t}}{D_{j t}}, \tilde{\alpha}=\alpha\left(\frac{\sigma-1}{\sigma}\right), \tilde{\beta}=\beta\left(\frac{\sigma-1}{\sigma}\right)$, and $\tilde{\gamma}=\gamma\left(\frac{\sigma-1}{\sigma}\right)$. We can then define $T F P_{i j t}=C_{j t} A_{i j t}^{\left(\frac{\sigma-1}{\sigma}\right)}$ or $\log \left(T F P_{i j t}\right)=\log \left(C_{j t}\right)+\left(\frac{\sigma-1}{\sigma}\right) \log \left(A_{i j t}\right)$, which captures the firm productivity measure used in our empirical results. Since $\log \left(T F P_{i j t}\right)$ is a linear transformation of $\log \left(A_{i j t}\right)$ within a group (same industry and year), the previous local misallocation losses remain the same if we replace real productivity with TFP in all previous steps.

\section{Appendix C - Assumptions for Quantification Exercise}

We provide a more detailed description of the assumptions we used for the different parameters in the quantification exercise. We use values for $\alpha$ and $\beta$ based on the estimates for $\widetilde{\alpha}$ and $\tilde{\beta}$ in our TFP estimation. From our analysis in Appendix B, we note that we can obtain $\alpha$ and $\beta$ as $\alpha=\left(\frac{\sigma}{\sigma-1}\right) \widetilde{\alpha}$ and $\beta=\left(\frac{\sigma}{\sigma-1}\right) \tilde{\beta}$. When choosing values for $\sigma$, we use three following Klenow and Hsieh (2009)

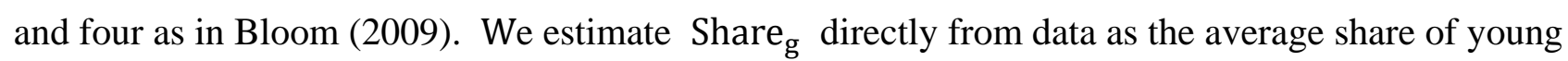
single-plant firms across industries, which is $56 \%$ in our sample. Notice that we are adding gains across all local industries, so we use the total share of this group in an industry. We measure 
empirically $a_{\mathrm{L}}^{\mathrm{g}}$ by first estimating a linear regression of MRPL on TFP (in logs) using singleestablishment young firms (age 1-10) in 1977 and include only states that have not been deregulated in that year. We include industry-state-age group fixed effects in this regression. This regression allows to predict $\log \left(1+\tau_{L}\right)$ with TFP (in logs) within a group prior to deregulation. This provides an initial value for $a_{\mathrm{L}}^{\mathrm{g}}$, which we then combine with the estimated effect from Table IX to also obtain a final value for $a_{\mathrm{L}}^{\mathrm{g}}$. We follow an analogous procedure for analyzing $a_{\mathrm{K}}^{\mathrm{g}}$. We obtain an empirical proxy for $\sigma_{\mathrm{Ag}}^{2}$ in the following way. For each industry (3-digit SIC code), state, and year, we first compute the standard deviation of TFP (in logs) within young (age 1-10) single-plant firms. We then take an average across different states and years to obtain a measure for each industry. We then sort all industries based on this measure. In our empirical analyses, we use the average value for all industries, as well as the average values for the top 50\% and top 33\% industries.

Using the initial and final values for $\left(a_{\mathrm{L}}^{\mathrm{g}}, a_{\mathrm{K}}^{\mathrm{g}}\right)$ and the other values previously explained, we can compute $\Delta \mathrm{LML}$. In order to convert these gross output gains into value-added gains, we scale $\Delta \mathrm{LML}$ (in gross output) by the average ratio of industry sales to industry value added (see Section VI). We convert this gain into an equivalent change in the output of young single-plant firms by dividing $\triangle \mathrm{LML}$ by the average share of output in young single-plant firms across industries. 
Figure 1: State Banking Deregulation Over Time

This figure presents the annual average value of the deregulation index across states during our sample period (19771993). Dereg is a banking deregulation index that equals the sum of Intrastate_Dereg and Interstate_Dereg. Intrastate_Dereg and Interstate_Dereg are indicators that equal one if the state has passed intrastate and interstate banking deregulation, respectively. Panel A repots the average value of Dereg for each year (across states). Panel B separately reports the average values of Inter_Dereg and Intra_Dereg for each year. See Section I.A for more details.

\section{Panel A: Deregulation Index Over Time}

\section{Average Value of Dereg Across States}

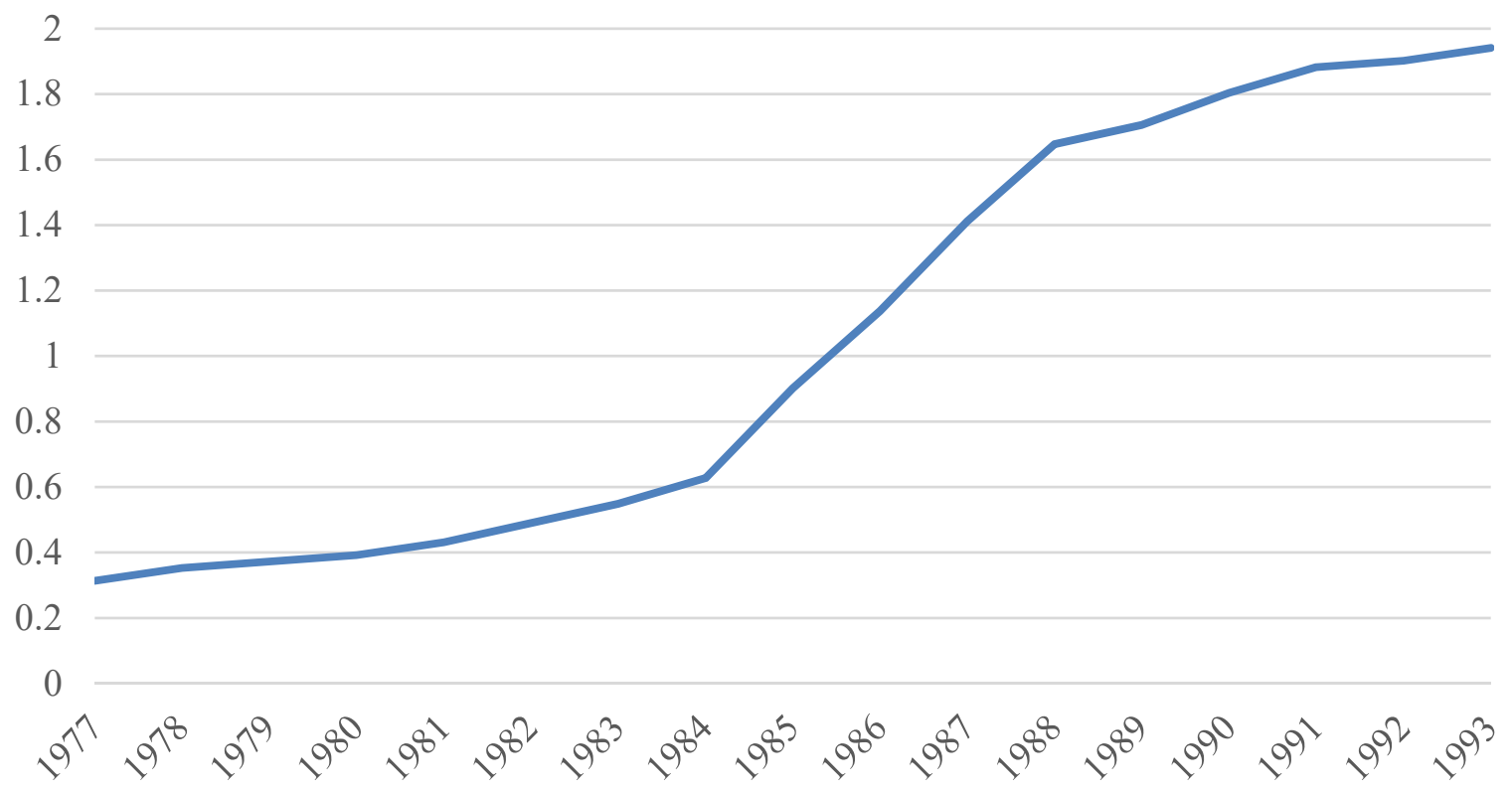

Panel B: Interstate and Intrastate Deregulation Over Time

Average Value of Inter Dereg and Intra Dereg Across States

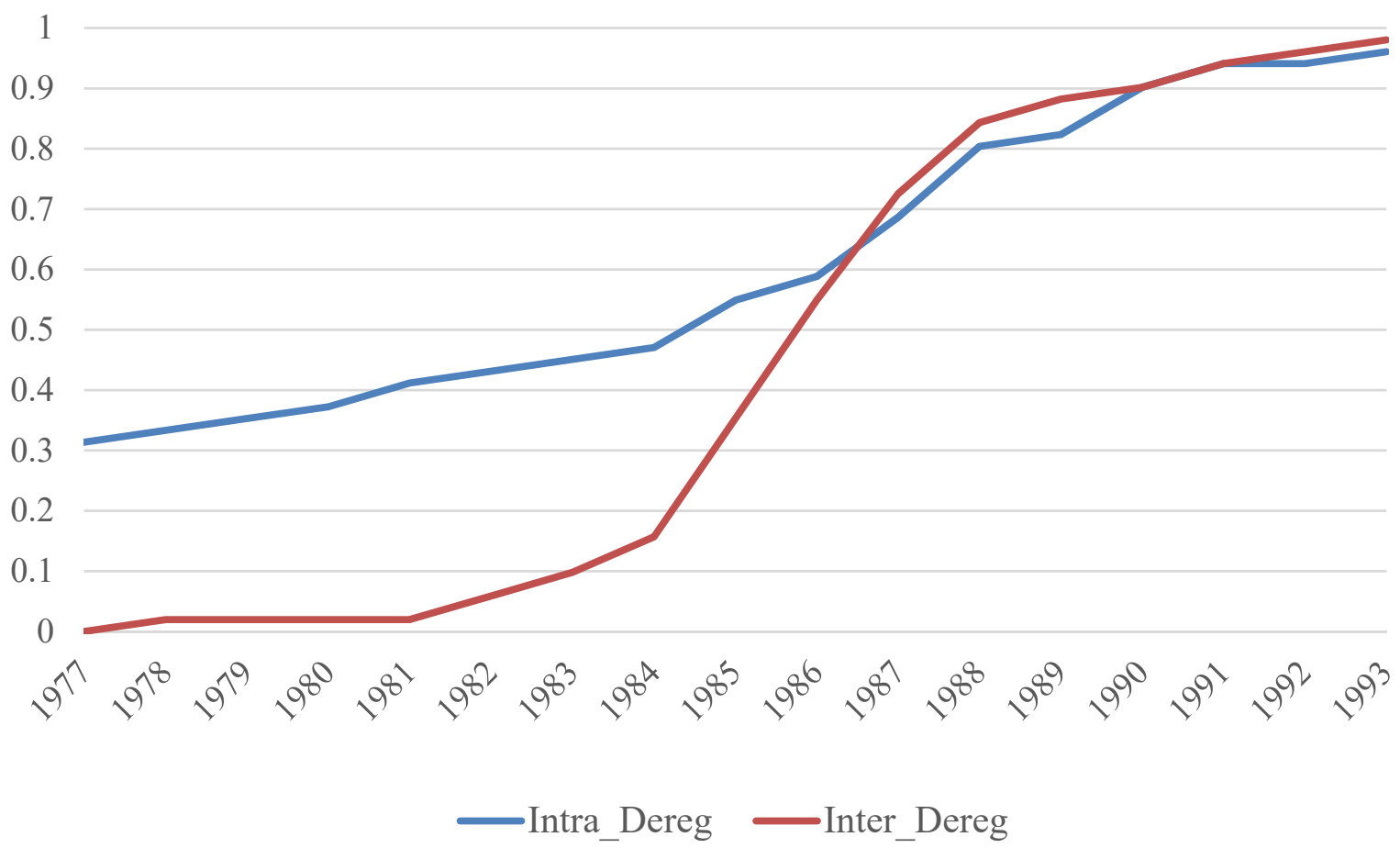


Figure 2

This figure analyzes the dynamics of the effects in Table V. The panels report results analogous to the ones in Table V with effects that are separately estimated across different years (1977, 1982, and 1987). For each specification in Table V, the variable Pre is replaced with three separate indictors for each of those three years (Year_1977, Year_1982, and Year_1987). These variables are included in an analogous way to Pre, including all previous controls based on them. The results in Panel A are based on the specification used in Panel B of Table V (Column (1)). The values reported for year $i$ represent the coefficient of Year_i $\times$ IDereg $\times$ TFP $\times$ Young. The results in Panel B are based on the specification used in Panel A of Table V (Columns (1) and (2)). The values reported for year $i$ represent the coefficient of Year_ $i \times I D e r e g$ $\times$ TFP for the respective age group (Young or Old). All reported effects are scaled in the same way as in Table V to capture a gap between the top and bottom quartiles of an industry-state.

\section{Panel A: Dynamics of Differential Effect for Young Firms}

Outcome: Bank Debt Share

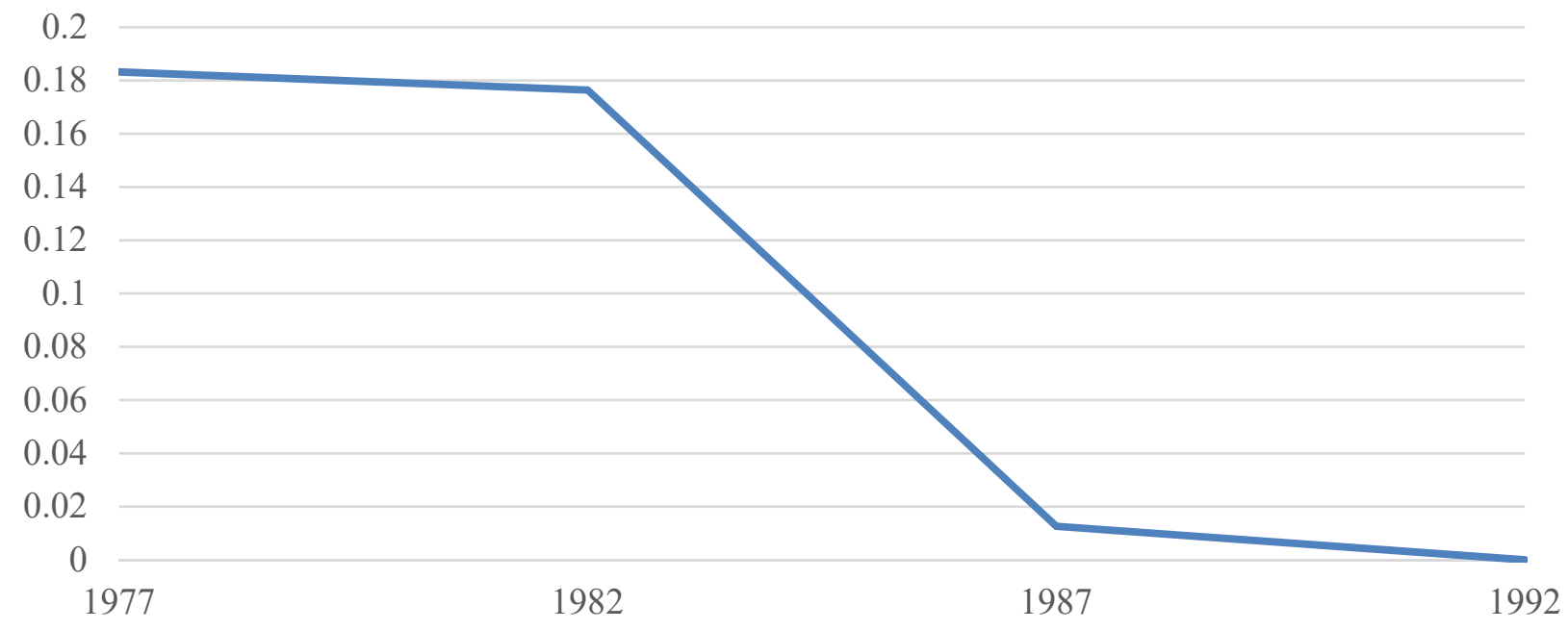

Panel B: Dynamics of Effects for Young and Old Firms

Outcome: Bank Debt Share

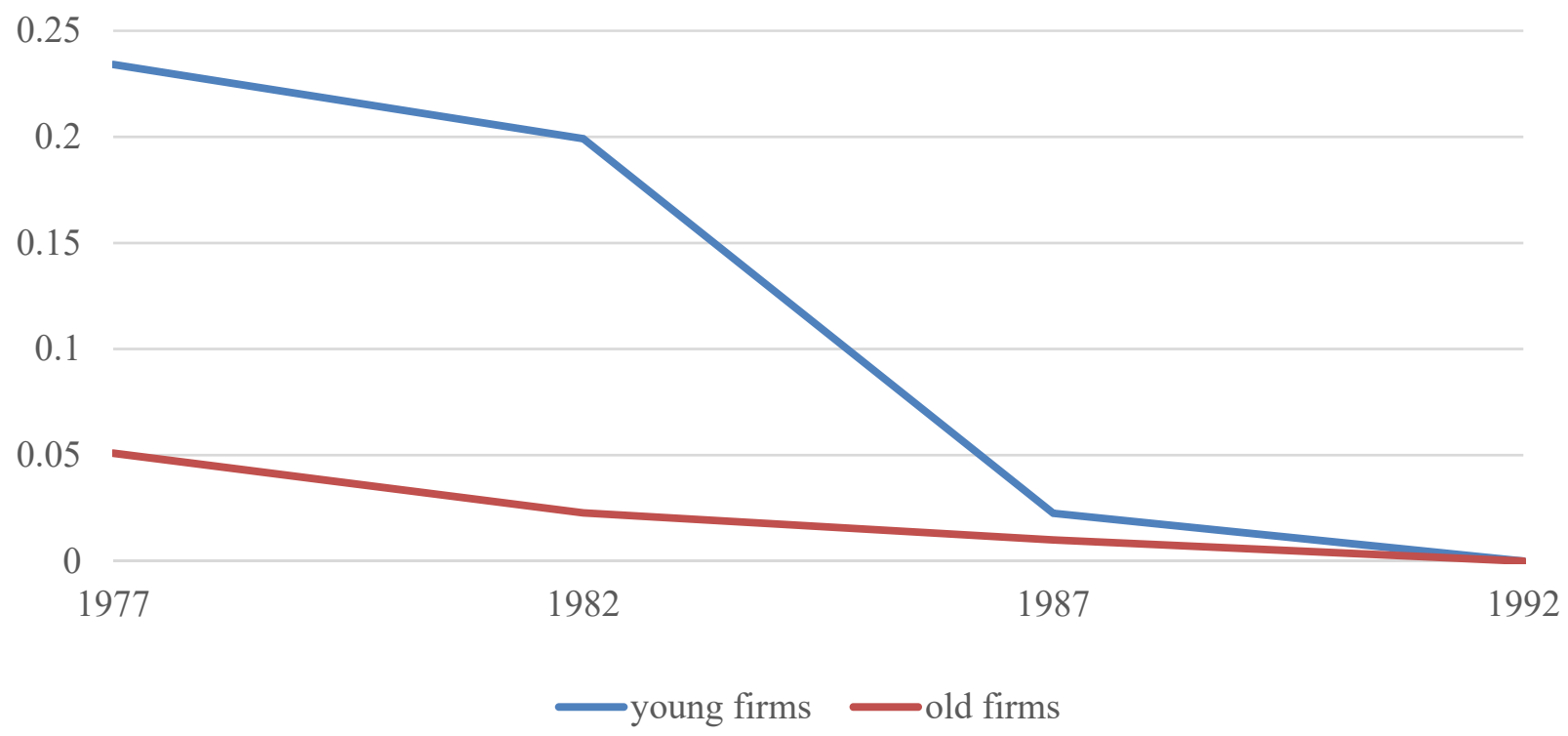




\section{Table I: Summary Statistics}

This table presents summary statistics for different variables used in the paper. Panel A shows summary statistics for the main sample used in the paper, which covers single-plant firms in the Longitudinal Business Database (LBD) that are also present in the previous Census of Manufacturers (CM). See the text for details. Young1 and Young2 are firms present for the first time in the previous CM and present for the first time in the CM before the previous one, respectively. Old includes all other firms in the main sample. Panel B reports summary statistics for the financial variables used in the paper. We use these variables in a sample of firms both present in the Quarterly Financial Reports (QFR) database and the CM. The means and standard deviations for this sample are computed using weights to match the distribution of size and age in our main sample. Young (Age 1-5) and Young (Age 6-10) are firms present for the first time in the current and previous $\mathrm{CM}$, respectively. Old (Age 11+) are all other firms in the sample. Variable definitions are in Appendix A. The number of observations has been rounded to the nearest hundred following the Census Bureau's disclosure policy.

\begin{tabular}{|c|c|c|c|c|c|c|c|c|c|c|c|c|}
\hline \multicolumn{13}{|c|}{ Panel A: Summary Statistics for Main Sample } \\
\hline & \multicolumn{3}{|c|}{ Full Sample } & \multicolumn{3}{|c|}{ Young1 } & \multicolumn{3}{|c|}{ Young2 } & \multicolumn{3}{|c|}{ Old } \\
\hline & Mean & StdDev & Nobs & Mean & StdDev & Nobs & Mean & StdDev & Nobs & Mean & StdDev & Nobs \\
\hline Employment Growth & $0.89 \%$ & $46.21 \%$ & $2,287,000$ & $5.74 \%$ & $55.20 \%$ & 742,000 & $-0.11 \%$ & $45.23 \%$ & 520,000 & $-2.11 \%$ & $38.65 \%$ & $1,025,000$ \\
\hline Employment & 22.28 & 46.23 & $2,287,000$ & 15.34 & 38.56 & 742,000 & 18.85 & 42.28 & 520,000 & 29.04 & 51.95 & $1,025,000$ \\
\hline Sales (\$1K 1987) & 1,446 & 4,047 & $2,287,000$ & 875.20 & $3,607.74$ & 742,000 & $1,105.85$ & $2,961.44$ & 520,000 & $1,906.29$ & $5,129.89$ & $1,025,000$ \\
\hline Dereg & 1.18 & 0.84 & $2,287,000$ & 1.15 & 0.84 & 742,000 & 1.17 & 0.84 & 520,000 & 1.22 & 0.84 & $1,025,000$ \\
\hline \multicolumn{13}{|c|}{ Panel B: Financial Variables (QFR Data) } \\
\hline & \multicolumn{3}{|c|}{ Full Sample } & \multicolumn{3}{|c|}{ Young (Age 1-5) } & \multicolumn{3}{|c|}{ Young (Age 6-10) } & \multicolumn{3}{|c|}{ Old (Age 11+) } \\
\hline & Mean & StdDev & Nobs & Mean & StdDev & Nobs & Mean & StdDev & Nobs & Mean & StdDev & Nobs \\
\hline Bank Debt Share & 0.56 & 0.36 & 19,000 & 0.54 & 0.37 & 2,000 & 0.56 & 0.36 & 3,000 & 0.57 & 0.36 & 14,000 \\
\hline Ratio of Bank Debt & 0.16 & 0.22 & 19,000 & 0.21 & 0.27 & 2,000 & 0.20 & 0.31 & 3,000 & 0.14 & 0.20 & 14,000 \\
\hline $\begin{array}{l}\text { Ratio of Non-bank } \\
\text { Debt }\end{array}$ & 0.13 & 0.32 & 19,000 & 0.21 & 0.39 & 2,000 & 0.19 & 0.45 & 3,000 & 0.11 & 0.28 & 14,000 \\
\hline
\end{tabular}


Table II: Banking Deregulation and Labor Reallocation

This table presents results linking state banking deregulation to changes in the relative employment growth of local firms with higher productivity. The analysis primarily focuses on the differential value of this effect for younger firms. The results are based on the estimation of interactions of Equation (1) with different age groups (Young1, Young2, and Old). The overall sample used in all results and the previous age groups are described in Panel A of Table I. The dependent variable is Employment Growth. Dereg is a banking deregulation index that equals the sum of Intrastate_Dereg and Interstate_Dereg. Intrastate_Dereg and Interstate_Dereg are indicators that equal one if the state has passed intrastate and interstate banking deregulation, respectively. TFP is a measure of firm productivity (in logs) based on plant-level data. Control variables include Large, Age1, Age2, and the interactions of each of these variables with the previous two deregulation indicators. Large is an indicator that equals one if the firm is above the median employment in a given year and age group (Young1, Young2, and other firms). Age1 measures the number of years since the firm first appeared in the LBD database and Age2 is the squared value of Age1. The results in Column (1) of Panel A consider the average effect of deregulation across all age groups. These results are based on the estimation of Equation (1) with additional controls, which include Young1, Young2, and their interactions with the two deregulation variables. Young1 and Young2 are indicators that equal one in these age groups. All other results consider the differential effect of deregulation for the age groups. In the specifications analyzing the differential effect for Young1, all independent variables (including controls) and fixed effects are included with and without their interaction with Young1. The only variables not interacted with Young1 are Age1 and Age2. The results analyzing the differential effects for both Young1 and Young2 are based on an analogous specification where the independent variables and fixed effects are now separately interacted with Young1 and Young2. The results in Columns (1) and (2) of Panel B exclude Age1, Age2 and their interactions from the set of controls. In the result in Column (3) of Panel B, Young1 is defined using the LBD as an indicator that equals one if Age1 $\leq 5$. In this result, only years from 1982 on are included. The results in Columns (1) and (2) of Panel C exclude Large and its interactions from the set of controls. The results in Columns (3) and (4) of Panel C replace Large with separate indicators for the four top quintiles of employment in a given year and age group. All interactions with Large in the set of controls are constructed in an analogous way for each of the four indicators. All coefficients are multiplied by the average TFP gap between the top and bottom quartiles of an industry-state (see text for details). The number of observations has been rounded to the nearest thousand following the Census Bureau's disclosure policy. Standard errors are heteroskedasticity robust and double clustered at the state and industry level. *,**, and *** indicate statistical significance at the $10 \%, 5 \%$, and $1 \%$, respectively.

Panel A: Main Specification

\begin{tabular}{|c|c|c|c|}
\hline \multicolumn{4}{|c|}{ Panel A: Main Specification } \\
\hline & \multicolumn{3}{|c|}{ Outcome: Employment Growth } \\
\hline & (1) & $(2)$ & (3) \\
\hline Dereg $\times$ TFP $\times$ Young 1 & & $\begin{array}{l}0.0149 * * * \\
(0.0019)\end{array}$ & $\begin{array}{l}0.0213 * * * \\
(0.0023)\end{array}$ \\
\hline Dereg $\times$ TFP $\times$ Young 2 & & & $\begin{array}{l}0.0151 * * * \\
(0.0026)\end{array}$ \\
\hline Dereg $\times$ TFP & $\begin{array}{l}0.0091 * * * \\
(0.0026)\end{array}$ & $\begin{array}{c}0.0026 \\
(0.0024)\end{array}$ & $\begin{array}{l}-0.0042 * * \\
(0.0022)\end{array}$ \\
\hline Year FE $\times$ TFP & Yes & & \\
\hline State FE $\times$ TFP & Yes & & \\
\hline Firm FE & Yes & & \\
\hline State-Industry-Year FE & Yes & & \\
\hline Year FE $\times$ TFP $\times$ Age Group & & Yes & Yes \\
\hline State FE $\times$ TFP $\times$ Age Group & & Yes & Yes \\
\hline Firm-Age Group FE & & Yes & Yes \\
\hline State-Industry-Year-Age Group FE & & Yes & Yes \\
\hline R-Square & 0.07 & 0.07 & 0.07 \\
\hline Nobs & $2,287,000$ & $2,287,000$ & $2,287,000$ \\
\hline
\end{tabular}


Outcome: Employment Growth

\begin{tabular}{lccc}
\hline & \multicolumn{2}{c}{ Age Controls Robustness } & LBD Age \\
\hline Dereg $\times$ TFP $\times$ Young1 & $(1)$ & $(2)$ & $(3)$ \\
& $0.0128^{* * *}$ & $0.0229^{* * *}$ & $0.0224 * * *$ \\
& $(0.0018)$ & $(0.0029)$ & $(0.0032)$ \\
Dereg $\times$ TFP $\times$ Young2 & & & \\
& & $0.0225^{* * *}$ & \\
Year FE $\times$ TFP $\times$ Age Group & & $(0.0040)$ & Yes \\
State FE $\times$ TFP $\times$ Age Group & Yes & Yes & Yes \\
Firm-Age Group FE & Yes & Yes & Yes \\
State-Industry-Year-Age Group FE & Yes & Yes & Yes \\
R-Square & Yes & & 0.07 \\
Nobs & & 0.07 & $1,687,000$ \\
\hline
\end{tabular}

\section{Panel C: Size Robustness}

Outcome: Employment Growth

\begin{tabular}{lcccc}
\hline & \multicolumn{2}{c}{ No Size Controls } & \multicolumn{2}{c}{ Additional Size Controls } \\
\hline Dereg $\times$ TFP $\times$ Young1 & $(1)$ & $(2)$ & $(3)$ & $(4)$ \\
& $0.0133^{* * *}$ & $0.0166^{* * *}$ & $0.0222^{* * *}$ & $0.0265^{* * *}$ \\
& $(0.0021)$ & $(0.0025)$ & $(0.0027)$ & $(0.0033)$ \\
Dereg $\times$ TFP $\times$ Young2 & & & $0.0105^{* * *}$ \\
& & $0.0084^{* * *}$ & & $(0.0034)$ \\
Year FE $\times$ TFP $\times$ Age Group & & $(0.0024)$ & & Yes \\
State FE $\times$ TFP $\times$ Age Group & & Yes & Yes \\
Firm-Age Group FE & & Yes & Yes & Yes \\
State-Industry-Year-Age Group FE & & Yes & Yes & Yes \\
R-Square & & Yes & & 0.07 \\
Nobs & 0.07 & 0.07 & $2,287,000$ & $2,287,000$ \\
\hline
\end{tabular}




\section{Table III: Banking Deregulation and Capital Reallocation}

This table presents results linking state banking deregulation to changes in the relative capital stock growth of local firms with higher productivity. The analysis focuses on the differential value of this effect for younger firms. The results are based on the same specification used in Table II (Columns (2) and (3) of Panel A) with a different outcome variable and the exclusion of firm fixed effects. The dependent variable is Capital Stock Growth. This outcome is only available during Census years and this prevents us from estimating the effect for Young1 with firm fixed effects (see text for details). All coefficients are multiplied by the average TFP gap between the top and bottom quartiles of an industry-state. The number of observations is rounded following Census Bureau's disclosure policy. Standard errors are heteroskedasticity robust and double clustered at the state and industry level. *,**, and $* * *$ indicate statistical significance at the $10 \%, 5 \%$, and $1 \%$, respectively.

\begin{tabular}{|c|c|c|}
\hline & \multicolumn{2}{|c|}{ Outcome: Capital Stock Growth } \\
\hline & $(1)$ & $(2)$ \\
\hline \multirow[t]{2}{*}{ Dereg $\times T F P \times$ Young 1} & $0.0040 * * *$ & $0.0041 * * *$ \\
\hline & $(0.0015)$ & $(0.0012)$ \\
\hline \multirow[t]{2}{*}{ Dereg $\times$ TFP $\times$ Young 2} & 0.0019 & \\
\hline & $(0.0014)$ & \\
\hline Year FE $\times$ TFP $\times$ Age Group & Yes & Yes \\
\hline State FE $\times$ TFP $\times$ Age Group & Yes & Yes \\
\hline State-Industry-Year-Age Group FE & Yes & Yes \\
\hline R-Square & 0.02 & 0.02 \\
\hline Nobs & 398,000 & 398,000 \\
\hline
\end{tabular}




\section{Table IV: Banking Deregulation and Labor Reallocation - Dynamics}

This table presents results on the dynamics of the effects of banking deregulation on the relative employment growth of local firms with higher productivity. As in Table II, the analysis focuses on the differential value of this effect for younger firms. The results are based on specifications similar to the ones in Table II (Column (3) of Panel A) that allow for pretrends on the effect of banking deregulation. These specifications add more variables to the one used in Table II. The specifications in Column (1) adds Dereg(-1 to -3) in analogous way to Dereg and includes the same set of interactions used for Dereg. The specification in Column (2) follows the same approach with Dereg(-1 to -6). All coefficients are multiplied by the average TFP gap between the top and bottom quartiles of an industry-state (see text for details). The number of observations has been rounded to the nearest thousand following the Census Bureau's disclosure policy. Standard errors are heteroskedasticity robust and double clustered at the state and industry level. *,**, and *** indicate statistical significance at the $10 \%, 5 \%$, and $1 \%$, respectively.

\begin{tabular}{|c|c|c|}
\hline \multicolumn{3}{|c|}{ Banking Deregulation and Labor Reallocation - Dynamics } \\
\hline & \multicolumn{2}{|c|}{ Outcome: Employment Growth } \\
\hline & $(1)$ & $(2)$ \\
\hline \multirow[t]{2}{*}{ Dereg $\times$ TFP $\times$ Young 1} & $0.0197 * * *$ & $0.0172 * * *$ \\
\hline & $(0.0026)$ & $(0.0029)$ \\
\hline \multirow[t]{2}{*}{ Dereg $\times$ TFP $\times$ Young 2} & $0.0126^{* * *}$ & $0.0115 * * *$ \\
\hline & $(0.0026)$ & $(0.0034)$ \\
\hline \multirow[t]{2}{*}{$\operatorname{Dereg}(-1$ to -3$) \times T F P \times$ Young 1} & 0.0002 & \\
\hline & $(0.0019)$ & \\
\hline \multirow[t]{2}{*}{$\operatorname{Dereg}(-1$ to -3$) \times T F P \times$ Young 2} & -0.0031 & \\
\hline & $(0.0023)$ & \\
\hline \multirow[t]{2}{*}{$\operatorname{Dereg}(-1$ to -6$) \times T F P \times$ Young 1} & & -0.0039 \\
\hline & & $(0.0025)$ \\
\hline \multirow[t]{2}{*}{$\operatorname{Dereg}(-1$ to -6$) \times \mathrm{TFP} \times$ Young 2} & & $-0.0052 * * *$ \\
\hline & & $(0.0019)$ \\
\hline Year FE $\times$ TFP $\times$ Age Group & Yes & Yes \\
\hline State FE $\times$ TFP $\times$ Age Group & Yes & Yes \\
\hline Firm-Age Group FE & Yes & Yes \\
\hline State-Industry-Year-Age Group FE & Yes & Yes \\
\hline R-Square & 0.07 & 0.07 \\
\hline Nobs & $2,287,000$ & $2,287,000$ \\
\hline
\end{tabular}


This table presents results linking banking deregulation to the relative importance of bank debt for local firms with higher productivity. The analysis contrasts the importance of this effect for different age groups. The dependent variable is Bank Debt Share, the ratio of bank debt to total debt (bank and nonbank debt). The results are based on the sample of firms described in Panel B of Table I, which includes firms that are both on the QFR database and the Census of Manufacturers (CM). Panel A reports results based on the estimation of Equation (2). Pre is an indicator variable that equals one prior to the deregulation wave (i.e., 1977 and 1982). IDereg is the initial (beginning of sample) value of banking deregulation index (Dereg). TFP is a measure of firm productivity (in logs) based on plant-level data. Control variables include Large, indicators for age groups, and the interactions of each of these variables with Pre, IDereg, and Prex IDereg. Large is an indicator that equals one for firms above the median value of employment in a given year and age group. Age groups are constructed based on the number of years since the firm first appeared in the CM (Age 1-5, Age 6-10, and Age 11+). The results are estimated in subsamples defined based on these age groups. Panel B estimates the differential value of the previous effects for groups of younger firms. In the specifications analyzing the differential effect for Young, all independent variables (including controls) and fixed effects are included with and without their interaction with Young. The only variables not interacted with Young are the age indicators. In the results where Young includes only firms with age between 1 and 5, all firms with age between 6 and 10 are excluded from the sample. Panel $\mathrm{C}$ reports results based on the estimation of Equation (3). Control variables include Large, indicators for age groups, and the interactions of each of these variables with Dereg. Panel D reports results based on the estimation of linear regression of Bank Debt Share on IDereg, Industry-Year fixed effects, Pre $\times$ IDereg, and controls. The controls include Large, indicators for age groups, and the interactions of these variables with Pre and IDereg. All coefficients in Panels A to C are multiplied by the average TFP gap between the top and bottom quartiles of an industry-state (see text for details). The number of observations has been rounded to the nearest thousand following the Census Bureau's disclosure policy. Standard errors are heteroskedasticity robust and double clustered at the state and industry level. *,**, and $* * *$ indicate statistical significance at the $10 \%, 5 \%$, and $1 \%$, respectively.

\begin{tabular}{lcccc}
\hline \multicolumn{5}{c}{ Panel A: Banking Deregulation and the Link Between Firm TFP and Bank Debt Share } \\
\hline \multicolumn{5}{c}{ Outcome: Bank Debt Share } \\
\hline & Young (Age 1-10) & Old (Age 11+) & Young (Age 1-5) & Young (Age 6-10) \\
\hline Pre $\times$ IDereg $\times$ TFP & $(1)$ & $(2)$ & $(3)$ & $(4)$ \\
& $0.2049 * * *$ & 0.0369 & $0.2937 * * *$ & $0.1767 * *$ \\
State-Industry-Year FE & $(0.0515)$ & $(0.0460)$ & $(0.0650)$ & $(0.0674)$ \\
Pre $\times$ TFP Control & Yes & Yes & Yes & Yes \\
IDereg $\times$ TFP Control & Yes & Yes & Yes & Yes \\
R-Square & Yes & Yes & Yes & 0.04 \\
& & & & 0.06 \\
Nobs & 0.04 & 0.02 & & 2,000 \\
\hline
\end{tabular}


Panel B: Differential Effect for Young Firms

Outcome: Bank Debt Share

\begin{tabular}{lccc}
\hline & Young (Age 1-10) & Young (Age 1-5) & \multicolumn{1}{c}{ Young (Age 6-10) } \\
\hline Pre $\times$ IDereg $\times$ TFP $\times$ Young & $(1)$ & $(2)$ & $(3)$ \\
& $0.1814 * * *$ & $0.2609 * * *$ & $0.1278^{* * *}$ \\
State-Industry-Year-Age Group FE & $(0.0648)$ & $(0.0997)$ & $(0.0454)$ \\
Pre $\times$ TFP $\times$ Age Group Controls & & & Yes \\
IDereg $\times$ TFP $\times$ Age Group Controls & Yes & Yes & Yes \\
& Yes & Yes & Yes \\
R-Square & & Yes & 0.02 \\
Nobs & 0.02 & & 13,000 \\
\hline
\end{tabular}

\section{Panel C: Alternative Specification}

Outcome: Bank Debt Share

\begin{tabular}{lcccc}
\multicolumn{5}{c}{ Outcome: Bank Debt Share } \\
\hline & Young (Age 1-10) & Old (Age 11+) & Young (Age 1-5) & Young (Age 6-10) \\
\hline Dereg $\times$ TFP & $(1)$ & $(2)$ & $(3)$ & $(4)$ \\
& $0.2215^{* * *}$ & 0.0691 & $0.3075^{* * *}$ & $0.158^{*}$ \\
Year FE $\times$ TFP & $(0.0310)$ & $(0.0601)$ & $(0.0822)$ & $(0.0724)$ \\
State-Industry-Year FE & Yes & Yes & Yes & Yes \\
& Yes & Yes & Yes & Yes \\
R-Square & & & & 0.04 \\
Nobs & 0.03 & 0.02 & 0.04 & 2,000 \\
\hline
\end{tabular}

Panel D: Average Effect of Banking Deregulation on Bank Debt Share

\begin{tabular}{lccc}
\hline Dependent Variable & \multicolumn{3}{c}{ Outcome: Bank Debt Share } \\
\hline & Full Sample & Young $(1-10)$ & Old $(11+)$ \\
\hline IDereg $\times$ Pre & $(1)$ & $(2)$ & $(3)$ \\
& 0.0083 & -0.0355 & 0.0256 \\
& $(0.0242)$ & $(0.0347)$ & Yes \\
Industry-Year FE & Yes & Yes & $0.0240)$ \\
& & & 0.01 \\
R-Square & 0.02 & 4,000 & 10,000 \\
Nobs & 14,000 & & \\
\hline
\end{tabular}


Table VI: What Happens to the Level of Bank and Non-Bank Debt?

This table estimates the results in Table V (Panels A to C) using the ratio of firms' bank debt and non-bank debt as outcome variables. Bank Debt Ratio is the ratio of bank debt to total assets. Non-Bank Debt Ratio is the ratio of non-bank debt to total assets. All coefficients in Panels A to C are multiplied by the average TFP gap between the top and bottom quartiles of an industry-state (see text for details). The number of observations has been rounded to the nearest thousand following the Census Bureau's disclosure policy. Standard errors are heteroskedasticity robust and double clustered at the state and industry level. *, **, and $* * *$ indicate statistical significance at the $10 \%, 5 \%$, and $1 \%$, respectively.

Panel A: Banking Deregulation and Changes in the Composition of Bank and Non-Bank Debt

Outcome: Bank Debt Ratio

Outcome: Non-Bank Debt Ratio

\begin{tabular}{lcccc}
\hline & Young (Age 1-5) & Old (Age 11+) & Young (Age 1-5) & Old (Age 11+) \\
\hline Pre $\times$ IDereg $\times$ TFP & $(1)$ & $(2)$ & $(3)$ & $(4)$ \\
& $0.1407 * * *$ & 0.0088 & -0.0532 & -0.0211 \\
State-Industry-Year FE & $(0.0462)$ & $(0.0177)$ & $(0.1131)$ & $(0.0215)$ \\
Pre $\times$ TFP Control & & & Yes & Yes \\
IDereg $\times$ TFP Control & Yes & Yes & Yes & Yes \\
& Yes & Yes & Yes & Yes \\
R-Square & Yes & Yes & 0.06 & 0.02 \\
Nobs & 0.06 & 0.02 & 2,000 & 10,000 \\
\hline
\end{tabular}

Panel B: Differential Effect for Young Firms

Outcome: Bank Debt Ratio Outcome: Non-Bank Debt Ratio

Young (Age 1-5)

\begin{tabular}{lcc}
\hline & $(1)$ & $(2)$ \\
\hline Pre $\times$ IDereg $\times$ TFP $\times$ Young & $0.1441^{* *}$ & -0.0273 \\
& $(0.0571)$ & $(0.1002)$ \\
State-Industry-Year-Age Group FE & Yes & Yes \\
Pre $\times$ TFP $\times$ Age Group Controls & Yes & Yes \\
IDereg $\times$ TFP $\times$ Age Group Controls & Yes & Yes \\
R-Square & & 0.02 \\
Nobs & 0.02 & 12,000 \\
\hline
\end{tabular}

Panel C: Alternative Specification

\begin{tabular}{lcccc}
\hline & \multicolumn{2}{c}{ Outcome: Bank Debt Ratio } & \multicolumn{2}{c}{ Outcome: Non-Bank Debt Ratio } \\
\hline & Young $($ Age 1-5) & Old (Age 11+) & Young (Age 1-5) & Old (Age 11+) \\
\hline Dereg $\times$ TFP & $(1)$ & $(2)$ & $(3)$ & $(4)$ \\
& $0.1294^{* * *}$ & $0.0383^{* *}$ & -0.0207 & 0.0233 \\
Year FE $\times$ TFP & $(0.0432)$ & $(0.0159)$ & $(0.0396)$ & $(0.0207)$ \\
State-Industry-Year FE & Yes & Yes & Yes & Yes \\
& Yes & Yes & Yes & Yes \\
R-Square & & & & 0.04 \\
Nobs & 0.04 & 0.02 & 1,000 & 9,000 \\
\hline
\end{tabular}


Table VII: Addressing Concerns About Bank Credit Demand Effects

This table presents results addressing concerns that changes in credit demand could explain the previous patterns for the share of bank debt. The results implement falsifications tests examining if higher local (state) economic growth is associated with a more positive link between firms' productivity and their bank debt share. The dependent variable in all results is Bank Debt Share, the ratio of bank debt to total firm debt. These results are based on the estimation of a specification analogous to one analyzed in Table V (Panel A), which replaces IDereg with Shock and replaces Pre with Post $=1$-Pre. The results include the same set of controls as in Table V, which are now defined in analogous way using Shock and Post. As in Table V, these effects are separately estimated for different age groups. The results in Panel A and B are based on different definitions for Shock. In Panel A, Shock is a predicted shock to state economic conditions between 1977 and 1993 (sample period). This shock is constructed by combining the initial (employment) composition of industries in each state with the realized national-level (employment) growth of different industries over the period (19771992). The predicted shock is the weighted average of national-level shocks to industries based on initial weights (see text and Appendix A for more details). In Panel B, Shock is the state's employment growth between 1977 and 1992. Panel $\mathrm{B}$ also includes the variable IDereg and all its interactions used in Table V as additional control variables. All coefficients are multiplied by the average TFP gap between the top and bottom quartiles of an industry-state and the standard deviation of Shock in the data. The number of observations has been rounded to the nearest thousand following the Census Bureau's disclosure policy. Standard errors are heteroskedasticity robust and double clustered at the state and industry level. *,**, and $* * *$ indicate statistical significance at the $10 \%, 5 \%$, and $1 \%$, respectively.

Panel A: Do Local Economic Shocks Lead to the Previous Patterns in Bank Debt Share?

Outcome: Bank Debt Share

(1)

Young Firms (Age 1-10)

TFP $\times$ Shock $\times$ Post

State-Industry-Year FE

Pre $\times$ TFP Control

Shock $\times$ TFP Control

R-Square

Nobs
0.0118

$(0.0330)$
$(2)$

Old Firms (Age 11+)

$-0.0197$

$(0.0275)$

$\begin{array}{cc}\text { Yes } & \text { Yes } \\ \text { Yes } & \text { Yes } \\ \text { Yes } & \text { Yes } \\ & \\ 0.02 & 0.02 \\ 4,000 & 9,000\end{array}$

Panel B: Is Local Economic Growth Associated with the Previous Patterns in Bank Debt Share?

Outcome: Bank Debt Share

(1)

Young Firms (Age 1-10)

Old Firms (Age 11+)

TFP $\times$ Shock $\times$ Post

$-0.0529$

0.0108

(0.0423)

(0.0261)

State-Industry-Year FE

Yes

Yes

Pre $\times$ TFP Control

Yes

Yes

Shock $\times$ TFP Control

Yes

Yes

IDereg $\times$ TFP Control

Yes

Yes

IDereg $\times$ TFP $\times$ Post Control

Yes

Yes

R-Square

0.04

0.02

Nobs

4,000

9,000 
Table VIII: Labor Reallocation Effects: Falsification Tests Examining Alternative Mechanisms

This table presents results addressing concerns that the previous labor reallocation effects are driven by alternative mechanisms, different from changes in the composition of bank credit supply. The results implement falsifications tests examining the effects of shocks to state economic conditions or shocks to specific local industries that shape firms' local demand, their input markets, or their labor markets. The dependent variable in all results is Employment Growth. These results are based on the estimation of a specification analogous to the one analyzed in Table II (Columns (2) and (3) of Panel A), which replaces Dereg with Shock. The results include the same set of controls as in Table II, which are now defined in analogous ways using Shock. The different panels are based on different definitions for Shock. In Panel A, Shock is a predicted shock to state economic growth between 1977 and the current year. This shock is constructed by combining the initial (employment) composition of industries in each state with the realized national-level (employment) growth of different industries over the period (1977-current year). The predicted shock is the weighted average of national-level shocks to industries based on initial weights (see text for more details). In Panel B, Shock is the state's employment growth between 1977 and the current year. Panel B also includes the variable Dereg and all its interactions used in Table II as additional control variables. In Panels C to E, Shock is a predicted shock to the growth of a subset of other local industries (in the same state) between 1977 and the current year. The shock to this subset of industries is predicted in an analogous way to the approach used in Panel A (using national-level shocks). For each industry-state, this subset of local industries includes only industries classified as connected at the national level. Connected industries are important consumers and suppliers in Panels $\mathrm{C}$ and D, respectively, based on Input-Output tables. Connected industries are industries with a similar workforce in Panel E. All coefficients are multiplied by the average TFP gap between the top and bottom quartiles of an industry-state and the standard deviation of Shock in the data. The number of observations has been rounded to the nearest thousand following the Census Bureau's disclosure policy. Standard errors are heteroskedasticity robust and double clustered at the state and industry level. $* * *$, and $* * *$ indicate statistical significance at the $10 \%, 5 \%$, and $1 \%$, respectively.

\begin{tabular}{lcc}
\hline \multicolumn{3}{c}{ Panel A: Effects of Shocks to State Economic Conditions (Predicted Shock) } \\
\hline & \multicolumn{1}{c}{ Outcome: Employment Growth } \\
\hline Shock $\times$ TFP $\times$ Young1 & $(1)$ & $(2)$ \\
Shock $\times$ TFP $\times$ Young2 & -0.0048 & $(0.0045)$ \\
& $(0.0049)$ & \\
Year FE $\times$ TFP $\times$ Age Group & $-0.0032^{* *}$ & Yes \\
State FE $\times$ TFP $\times$ Age Group & $(0.0015)$ & Yes \\
Firm-Age Group FE & & Yes \\
State-Industry-Year-Age Group FE & Yes & Yes \\
R-Square & Yes & 0.01 \\
Nobs & Yes & $2,287,000$ \\
\hline
\end{tabular}




\section{Panel B: Effects of Local Economic Conditions (Realized Growth)}

\begin{tabular}{lcc}
\hline & \multicolumn{2}{c}{ Outcome: Employment Growth } \\
\hline Shock $\times$ TFP $\times$ Young1 & $(1)$ & $(2)$ \\
Shock $\times$ TFP $\times$ Young2 & 0.0009 & $(0.0005$ \\
& $(0.0022)$ & \\
& 0.0013 & $(0.0010)$ \\
Year FE $\times$ TFP $\times$ Age Group & & Yes \\
State FE $\times$ TFP $\times$ Age Group & Yes & Yes \\
Dereg $\times$ TFP $\times$ Age Group & Yes & Yes \\
Firm-Age Group FE & & Yes \\
State-Industry-Year-Age Group FE & Yes & Yes \\
R-Square & & 0.01 \\
Nobs & $2,287,000$ \\
\hline
\end{tabular}

Panel C: Local Demand Effects

Outcome: Employment Growth

\begin{tabular}{lcc}
\hline & $(1)$ & $(2)$ \\
\hline Shock $\times$ TFP $\times$ Young1 & -0.0022 & -0.0039 \\
Shock $\times$ TFP $\times$ Young2 & $(0.0016)$ & $(0.0023)$ \\
& 0.0009 & \\
Year FE $\times$ TFP $\times$ Age Group & $(0.0011)$ & Yes \\
State FE $\times$ TFP $\times$ Age Group & Yes & Yes \\
Firm-Age Group FE & Yes & Yes \\
State-Industry-Year-Age Group FE & Yes & Yes \\
R-Square & Yes & 0.01 \\
Nobs & & $2,287,000$ \\
\hline
\end{tabular}


Outcome: Employment Growth

\begin{tabular}{lcc}
\hline & $(1)$ & $(2)$ \\
\hline Shock $\times$ TFP $\times$ Young1 & 0.0004 & 0.0002 \\
Shock $\times$ TFP $\times$ Young2 & $(0.0003)$ & $(0.0002)$ \\
& 0.0008 & \\
Year FE $\times$ TFP $\times$ Age Group & $(0.0006)$ & \\
State FE $\times$ TFP $\times$ Age Group & Yes & Yes \\
Firm-Age Group FE & Yes & Yes \\
State-Industry-Year-Age Group FE & Yes & Yes \\
R-Square & Yes & Yes \\
Nobs & & 0.01 \\
\hline
\end{tabular}

\section{Panel E: Effects of Shocks to Local Labor Markets}

Outcome: Employment Growth

\begin{tabular}{lcc}
\hline & $(1)$ & $(2)$ \\
\hline Shock $\times$ TFP $\times$ Young1 & 0.0004 & 0.0000 \\
Shock $\times$ TFP $\times$ Young2 & $(0.0022)$ & $(0.0017)$ \\
& 0.0007 & \\
Year FE $\times$ TFP $\times$ Age Group & $(0.0014)$ & \\
State FE $\times$ TFP $\times$ Age Group & Yes & Yes \\
Firm-Age Group FE & Yes & Yes \\
State-Industry-Year-Age Group FE & Yes & Yes \\
R-Square & Yes & 0.01 \\
Nobs & & $2,287,000$ \\
\hline
\end{tabular}


Table IX: Are the Results Associated with a Convergence of Marginal Products?

This table reports results linking state banking deregulation to gaps between the marginal revenue product of local firms with high and low productivity. The analysis focuses on the differential effects for young local firms. The results are based on the same specifications used in Table VI with different outcome variables (MRPL and MRPK). MRPL is the log of the ratio of revenues to total labor. MRPK is the log of the ratio of revenues to the capital stock. Columns (1), (3), and (6) are based on the specification in Panel B of Table VI. Columns (2), (4), and (5) report differential effects for younger firms based on the estimation of the specification in Panel C of Table VI for different age groups. All independent variables (including controls) and fixed effects in the previous specification are now included with and without their interaction with Young. The only variables not interacted with Young are the age indicators. All coefficients are multiplied by the average TFP gap between the top and bottom quartiles of an industry-state (see text for details). The number of observations has been rounded to the nearest thousand following the Census Bureau's disclosure policy. Standard errors are heteroskedasticity robust and double clustered at the state and industry level. *, **, and $* * *$ indicate statistical significance at the $10 \%, 5 \%$, and $1 \%$, respectively.

\begin{tabular}{|c|c|c|c|c|c|c|}
\hline & \multicolumn{5}{|c|}{ Outcome: MRPL } & \multirow[t]{2}{*}{ Outcome: MRPK } \\
\hline & \multicolumn{2}{|c|}{ Young (Age 1-5) } & \multicolumn{3}{|c|}{ Young (Age 1-10) } & \\
\hline & (1) & (2) & (3) & (4) & $(5)$ & (6) \\
\hline Pre $\times$ IDereg $\times$ TFP $\times$ Young & $\begin{array}{l}-0.0280 * * * \\
(0.0094)\end{array}$ & & $\begin{array}{l}-0.0254 * * * \\
(0.0074)\end{array}$ & & & $\begin{array}{c}-0.0208 * * \\
(0.0101)\end{array}$ \\
\hline Dereg $\times$ TFP $\times$ Young & & $\begin{array}{l}-0.0508 * * * \\
(0.0138)\end{array}$ & & $\begin{array}{l}-0.0380 * * * \\
(0.0106)\end{array}$ & $\begin{array}{l}-0.0417 * * * \\
(0.0084)\end{array}$ & \\
\hline State-Industry-Year-Age Group FE & Yes & Yes & Yes & Yes & Yes & Yes \\
\hline $\begin{array}{l}\text { Pre } \times \text { TFP } \times \text { Age Group Controls } \\
\text { IDereg } \times \text { TFP } \times \text { Age Group }\end{array}$ & Yes & & Yes & & & Yes \\
\hline Controls & Yes & & Yes & & & Yes \\
\hline Year FE $\times$ TFP $\times$ Age Group & & Yes & & Yes & Yes & \\
\hline State FE $\times$ TFP $\times$ Age Group & & Yes & & Yes & & \\
\hline R-Square & 0.01 & 0.01 & 0.01 & 0.01 & 0.01 & 0.01 \\
\hline Nobs & 413,000 & 430,000 & 542,000 & 564,000 & 564,000 & 549,000 \\
\hline
\end{tabular}


Table X: Quantification of Implied Industry Productivity Gains

This table reports the magnitudes for the industry productivity gains implied by the previous results in a standard model of misallocation and industry productivity (see Section V.Cand Appendix C for details). The analysis considers a change in the link between labor and capital distortions and the productivity of single-plant young firms within a same industrystate. The analysis assumes that this link changes for all states in which an industry operates at the same time. This link drops by the amount implied by the results in Table IX (Columns (1) and (6)). Panels A and B report the implied gains for aggregate industry productivity computed using Equation (4) and plausible assumptions about the underlying parameters. Industry VA Gain (\%) captures the implied percentage increase in industry value added. Drop in Local Misallocation (\%) measures the percentage drop in the local misallocation loss described in Section IV. Firm Productivity Effect measures the equivalent percentage increase in the output of all individual young single-plant firms necessary to generate the same gain in aggregate industry value added. The values implied by different values of the demand elasticity faced by firms $(\sigma)$ are reported separately. The results are also estimated separately for different values of the dispersion in firm productivity. All TFP SD uses the average value of this dispersion in the sample of all industries. Top 50\% SD and Top 33\% SD use the average value of this dispersion in the top 50\% and top 33\% of industries in terms of this dispersion. Panel $\mathrm{C}$ analyzes the percentage contribution of labor and capital to these gains along the lines described in the text (Section V.C).

\begin{tabular}{lccc}
\hline \multicolumn{4}{c}{ Panel A: Implied Gains for Industry Output } \\
\hline & Sigma =3 \\
\hline All TFP SD & Industry VA Gain (\%) & Drop in Misallocation (\%) & Firm Prod. Effect (\%) \\
Top 50\% TFP SD & $1.1 \%$ & $24.3 \%$ & $3.3 \%$ \\
Top 33\% TFP SD & $1.7 \%$ & $24.3 \%$ & $4.9 \%$ \\
\hline
\end{tabular}

\begin{tabular}{lccc}
\hline \multicolumn{4}{c}{ Panel B: Implied Gains for Industry Output - Continuation } \\
\hline \multicolumn{4}{c}{ Sigma $=4$} \\
\hline All TFP SD & Industry VA Gain (\%) & Drop in Misallocation (\%) & Firm Prod. Effect (\%) \\
Top 50\% TFP SD & $1.2 \%$ & $24.4 \%$ & $3.5 \%$ \\
Top 33\% TFP SD & $1.8 \%$ & $24.4 \%$ & $5.2 \%$ \\
\end{tabular}

Panel C: Contribution of Labor and Capital Effects

\begin{tabular}{ccc}
\hline & Sigma $=3$ & Sigma $=4$ \\
\hline $\begin{array}{c}\text { \% Gain from Capital } \\
\text { Misallocation Effect }\end{array}$ & $14 \%$ & $15 \%$ \\
$\%$ Gain from Labor & $86 \%$ & $85 \%$ \\
Misallocation Effect & $86 \%$ \\
\hline
\end{tabular}

